\title{
Sociabilidades en las plazas de Buenos Aires. Usos, usuarios y diseño urbano
}

\section{Sociabilities on the town squares of Buenos Aires. Uses, users and urban design}

Carmen Egea Jiménez*

Edwar Leonardo Salamanca Ospina**

\begin{abstract}
Resumen
Este artículo es parte de una investigación más amplia sobre el análisis de los espacios públicos y las plazas desde el enfoque de la sociabilidad, planteándose aqui una reflexión teórica-metodológica sobre tres plazas de Buenos Aires: Madero Harbour, Lavalle y España. Se usan tres herramientas de análisis: la caminata urbana, el cuaderno de campo y la encuesta. Algunos resultados señalan que la sociabilidad está presente de muchas formas en las tres plazas; que las personas disfrutan el espacio junto con personas conocidas y en contacto con extrañas; que el uso desarrolla una experiencia espacial creativa más allá del diseño; y que la distancia no es determinante para su uso.
\end{abstract}

Palabras clave: espacios públicos; plazas; sociabilidad; prácticas socioespaciales; caminata urbana.

\begin{abstract}
The article is part of a broader research on the analysis of public spaces and places from the approach of sociability, considering a theoretical-methodological reflection focused on three squares of Buenos Aires: Madero Harbour, Lavalle and Spain. Three analysis tools are used: the urban walk, the field notebook and the survey. Some results indicate that sociability is present in many ways in the three places;

* Universidad de Granada. Dirección: Departamento de Geografía Humana, Facultad de Filosofía y Letras, Universidad de Granada, campus Cartuja, 18071, Granada, España. Correo: cegea@ugr.es. ORCID: http://orcid.org/0000-0002-6629-6890

** Universidad de Granada. Docente de la Secretaría de Educación de Distrito (SED) Bogotá. Dirección: El Dorado 66-63, CP. 111321, Bogotá, Colombia. Correo: teleologías@ yahoo.es ORCID: https://orcid.org/0000-0001-6930-8423
\end{abstract}


that people enjoy the space together with familiar people and in contact with strangers; that the use develops a creative spatial experience beyond the design; and that distance is not decisive for its use.

Keywords: public spaces; town squares; sociability; socio-spatial practices; urban travel.

\section{Introducción}

El espacio público es el "escenario" en el que se entreteje el sistema de valores de una comunidad, en tanto su construcción socioespacial parte de un proceso de apropiación y pertenencia, acelerado por la simbiosis entre el diseño urbano y las características de la persona, grupo o comunidad que lo usa.

Tienen en común el hecho de ser abiertos y accesibles, contar con disponibilidad de infraestructura y permitir la realización de actividades individuales o grupales [...]. Son espacios para la permanencia (estar, mirar y pasear) [y] para la visibilidad de las diferencias [Makowski 2003, en Petzold, 2017, p. 28].

Para los fines de este texto, sin olvidar que se trata de una noción polisémica (Ramírez, 2007; Carrasco, 2011), este concepto se aleja de definiciones que sitúan el espacio público en la esfera política (Rabotnikof, 2008; Sousa, 2013), y se acerca a dimensiones de análisis que, como la apropiación, la pertenencia y las prácticas cotidianas, están directamente relacionadas con la experiencia espacial del espacio vivido (Lindón, Hiernaux-Nicolas y Aguilar, 2006). Las prácticas cotidianas o socioespaciales implican el sentido del lugar (Fu-Tuan, 1977; Ortiz, 2006; Ramírez, 2016), que, si bien genera confianza y seguridad, también puede conllevar situaciones de conflicto entre los usuarios por su uso (Salmenkari, 2009; Motta, Rosa y García, 2013; Ayala, 2015; Boy, Marcus y Perelman, 2015; Boy, 2018; Perelman, 2018).

Un aspecto que remarca precisamente el carácter de lugar de los espacios públicos es su capacidad para generar interacciones personales y colectivas a través de encuentros deliberados o aleatorios y mediante estrategias visuales, corporales, comportamentales, sonoras, gestuales (Gomes y Parente, 2018). Esta capacidad es la que hace posible la sociabilidad (García del Villar, 2018), la cual la puso de manifiesto Kropotkin (1842-1921) ${ }^{1}$ al referirse a ella como la necesidad de relacionarnos para sobrevivir en socie-

\footnotetext{
${ }^{1}$ Consúltese la obra El apoyo mutuo: un factor en la evolución (1902).
} 
dad, considerando que son las sociedades que tienen un grado de sociabilidad más alto las más desarrolladas socialmente. Este mismo concepto será desarrollado desde la sociología por Georg Simmel (1858-1918) y Georges Gurvitch (1894-1965). Ambos sientan las bases de la sociabilidad como paradigma para responder "cómo es posible la sociedad -Simmel- y la manera en y por lo que se relacionan los individuos -Gurvitch-" (Vega, 2015, p. 2). Para Simmel es:

[...] una dinámica esencial de la realidad social, es decir, algo puro que no se delimita o relaciona a intereses materiales, constituyéndose en un aspecto espontáneo del individuo [...], instintiva, sin pasar por la racionalidad del cerebro [Chapman, 2015, p. 14].

\section{Para Gurvitch,}

[...] las relaciones sociales no son posibles sin las estructuras sociales, sin marcos de referencia como las asociaciones, la familia, el café, etc., lo que establece la existencia de varios tipos de sociabilidad de acuerdo con sus dinámicas organizacionales y culturales, convirtiéndose en un fenómeno social o hecho social que estará mediado por reglas fuera del individuo, pero que son interiorizadas por éste con el objetivo de establecer un accionar social [Chapman, 2015, p. 14].

Ambas perspectivas resultan complementarias: la sociabilidad entendida como un elemento espontáneo de la realidad social, pero regulado por la norma (Treviño, 2013).

En los espacios públicos, la sociabilidad está dada por ser ahí donde se visibilizan las diferentes formas de interacción, uso y apropiación del espacio, lo cual los dota de múltiples significados y expresa diferentes formas de construir ciudadanía, hasta consolidarse el espacio público en el imaginario social como "el espacio de todos" (Ramírez, 2007, p. 104). ${ }^{2}$

La atención de este estudio se focaliza en un espacio público concreto: la plaza, donde interesa analizar los elementos que la definen como un ente con vida propia (Gomes, 2012), como vehículo para la sociabilidad, como un espacio social: "las plazas son espacios libres públicos, con función de convivencia social, insertados en la malla urbana, como elemento organizador de la circulación y amenización pública" (Sousa, 2013, p.

${ }^{2}$ Algunos estudios del espacio público desde la sociabilidad son los de Giglia, 2001; Andrade, Jayme y Almeida, 2009; Siborí, 2005; Torres, 2008; Lamborghini, 2015; Berneth, 2016; Rubio, 2016; Simonetto, 2017. 
299); ofrecen emoción y descanso, comercio y ceremonias públicas, un lugar para encontrar amigos y ver el mundo pasar (Webb, 1990); es el lugar intencional del encuentro, de los acontecimientos, de las prácticas sociales, de las manifestaciones de la vida urbana comunitaria y de las funciones de la estructura urbana (Lamas, 1993); el ámbito de la visibilidad, donde se adquiere la cualidad de actor social (Casseti y Lietti, 1995); son los lugares para ver y ser visto, para hacer negocios, para pasear y hacer política (Spirn, 1995). ${ }^{3}$

El análisis se centra en tres plazas de la Ciudad de Buenos Aires; dos situadas en la Comuna 1: Plaza Madero Harbour (barrio Puerto Madero) y Plaza Lavalle (barrio San Nicolás); y otra en la Comuna 4, Plaza España, también mencionada como Parque (barrio Barracas) (Mapa 1).

\section{Mapa 1}

Ubicación de las plazas de estudio

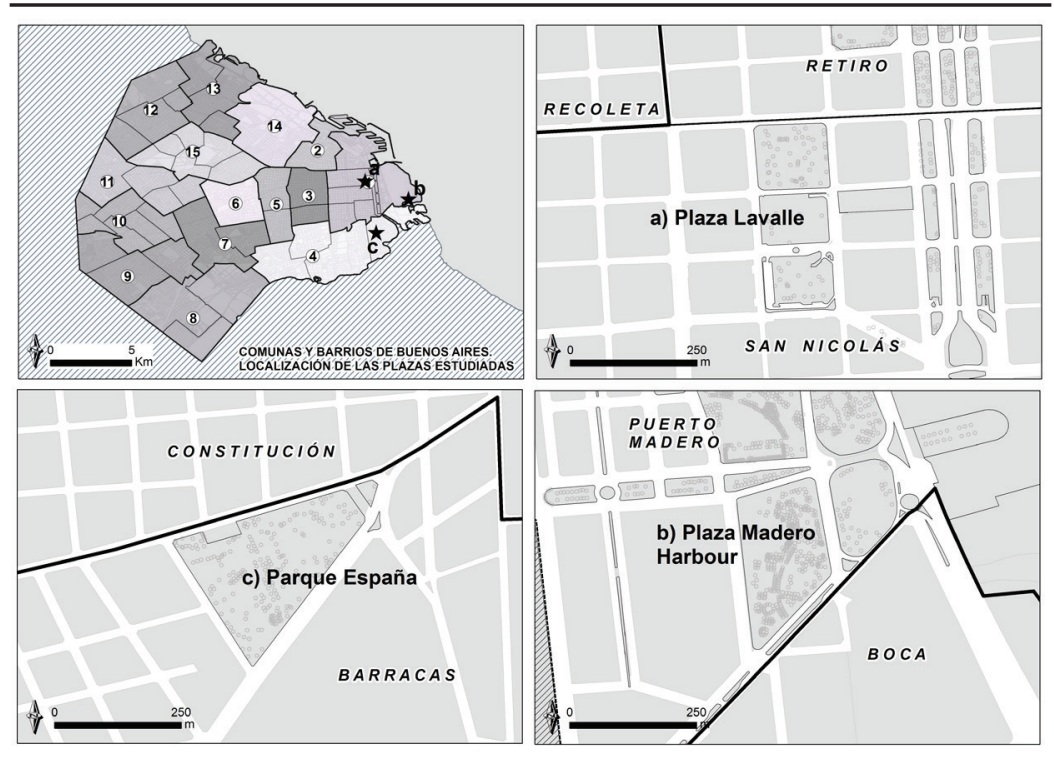

Fuente: Elaboración propia.

${ }^{3}$ Sobre las plazas en América Latina se pueden consultar los estudios de Scobie, 1982; Low, 1997; Barbosa y Pérez, 1998; Berjman, 1998; Barros y Virgilio, 2003; Serpa, 2003; Scarpaci, 2005; Licona, 2007; Gomes, 2007; Frehse, 2013; Salazar, 2017. 
La pregunta de investigación que se plantea es: ¿qué elementos definen la sociabilidad en estas tres plazas teniendo en cuenta su localización, diseño, prácticas de apropiación y relaciones sociales que tejen sus usuarias/os? El objetivo gira en dar respuesta a esta pregunta y analizar los elementos que definen la sociabilidad de las plazas objeto de estudio, contenedoras de atributos diferentes.

Con este trabajo se defiende la hipótesis de que las plazas se resisten a la idea de crisis o fin de los espacios públicos (Finol, 2005; Sousa, 2013; Brandis y Del Río, 2016); son un buen barómetro para medir el nivel de integración social y sentido democrático de una sociedad (Rizzo, 2010); y un buen indicador de la calidad de vida urbana (Páramo, 2010).

El trabajo se estructura de la siguiente manera: a continuación se presenta un apartado sobre la localización e historia de las plazas investigadas; le sigue la explicación de la metodología usada; posteriormente hay un apartado donde se analiza la sociabilidad en cada plaza; a continuación, otra sección donde se ponen en diálogo las tres plazas, analizando los elementos transversales (y también particulares) que definen la sociabilidad; finalmente, se presentan las conclusiones y la bibliografía referida en el texto, con la cual se ha pretendido enmarcar el tema investigado, sobre todo en el ámbito de América Latina.

\section{Localización y breve historia de las plazas}

El planeamiento de la Ciudad de Buenos Aires se caracteriza por un sistema de plazas y parques proyectado desde la emblemática Plaza de Mayo. Desde finales del siglo XIX y durante las tres primeras décadas del siglo XX, el desarrollo urbano de la ciudad es incipiente debido a "su centralidad, el papel del puerto y la función de capital virreinal y después nacional" (Delgadillo, 2011, p. 271). Es también en estas décadas cuando, como en otras ciudades de América Latina y Europa, se acometen reformas importantes de saneamiento y embellecimiento bajo la influencia de lo que se conoce como "estilo francés", a tenor del impacto del diseño urbano de Haussman (1801-1891) en París (Romero, 1999; Salazar, 2007; Arango, 2012; Segarra, 2016). Esto explica que en muchas ciudades proliferen parques y plazas concebidas también como espacios verdes. ${ }^{4}$

${ }^{4}$ En el caso de la ciudad de Buenos Aires se pueden señalar: Plaza del Congreso, Plaza San Martín, Plaza Lavalle, Paseo de la Recoleta, Parque Tres de Febrero, Plaza Belgrano, Plaza Flores, Parque Centenario, Parque Chacabuco, Parque Avellaneda, Parque Patricios y Plaza Devoto. 
Más recientemente, y dando un salto en el tiempo, la mayor parte de las ciudades se encuentran inmersas en procesos de renovación urbana cuya principal preocupación, desde la década de 1980, es la de recuperar el centro como sello de identidad de la ciudad por su capacidad para atraer inversores, recuperar y poner en valor el patrimonio histórico y potenciar el sector turístico (Carrión, 2001; Rojas 2004; Delgadillo, 2011; Salinas, 2013). En este sentido, en Buenos Aires se desarrolla el Plan de Marketing Turístico (2007), en el que queda patente la alianza cultura y turismo (Rodríguez, Arqueros, Rodríguez, Gómez y Zapata, 2011) y la creación de la marca Buenos Aires, con la renovación, principalmente, de los barrios de San Telmo y La Boca (Marcús, 2012).

En el caso de este estudio, dos de las plazas analizadas -Plaza Lavalle y Madero Harbour- se encuentran en una de las comunas que conforman dicho centro: la Comuna 1, situada en la parte más al este de la Zona Centro y una de las que cuenta con más atractivos turísticos por su patrimonio. Por su parte, la Plaza España se encuentra en la Comuna 4 -Zona Sur-, en el límite con el barrio Constitución (Comuna 1). La Comuna 4 ha sido desde 1996 una de las zonas estratégicas del Plan Urbano Ambiental, con la intención de superar problemas de precarización y convertirla en un espacio competitivo. Con el Plan de Ordenamiento del Área Central se ha intentado limitar su función administrativa y de negocios, promoviendo el uso residencial desde la rehabilitación, peatonalización y expansión hacia el sur. Esto explica que en el barrio Barracas de esta comuna se promueva el uso residencial para una clase media-alta, la localización de distritos administrativos y proyectos con implicaciones en el mantenimiento del tejido social y económico tradicional (Herzer y Gil, 2012).

Si bien las tres plazas son espacios públicos de uso y acceso libre y de titularidad pública, cada una tiene una forma de ser marcada por su propia historia, que las hace diferentes mostrándose como ejemplos de diversidad de interacciones, usos y apropiaciones, en definitiva, de sociabilidades diferentes.

Así, la Plaza Lavalle hace honor al General Juan Galo Lavalle (17971841). Durante mucho tiempo fue una estación, conociéndose como Estación de El Parque. En 1878 adquiere el nombre con el que se le conoce en la actualidad. Desde sus orígenes ha sido un lugar de gran dinamicidad en la historia cívica y social de la ciudad (Fotografía 1). Se trata de un gran espacio situado en el sector central de la urbe; comprende tres manzanas entre la avenida Córdoba y Lavalle y la calle Talcauhano y Libertad. Está rodeada de edificios históricos, culturales e institucionales: Teatro Colón, Palacio de Justica y Teatro Nacional Cervantes; y próxima al Obelisco, uno de los lu- 
gares emblemáticos de Buenos Aires. Es el epicentro de diferentes hechos históricos desde las primeras décadas del siglo XIX, y como se verá a continuación, también lugar de continuas reivindicaciones.

\section{Fotografía 1}

Plaza Lavalle, cerca de 1900

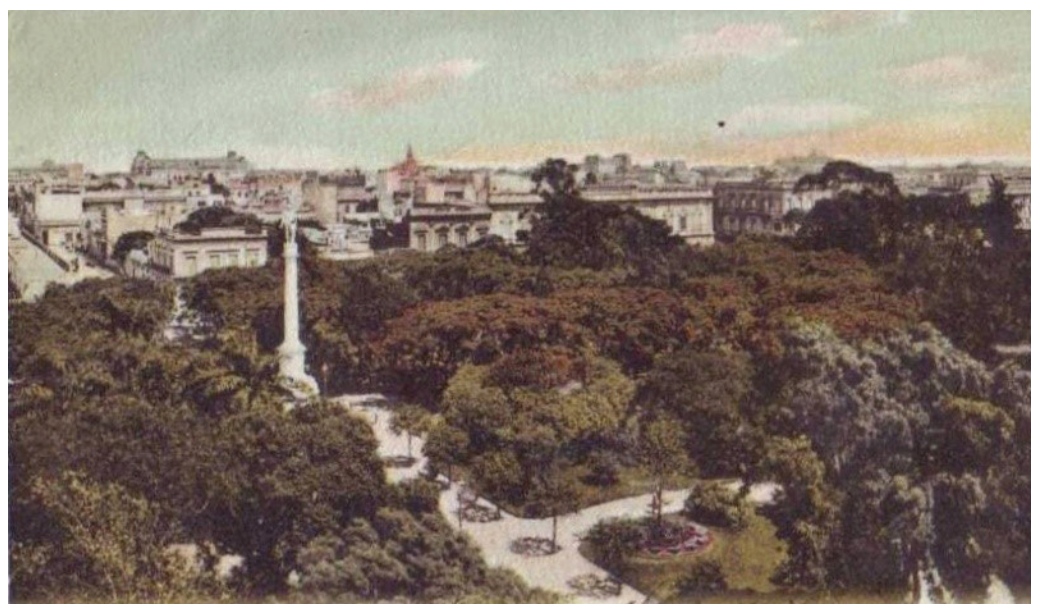

Fuente: http://www.arcondebuenosaires.com.ar/plaza_lavalle.htm (consultado el 25 de abril de 2019).

La Plaza Madero Harbour, o Plaza María Eva Duarte de Perón -en honor a este personaje (1919-1952) de la historia del país-, es relativamente reciente, quedando inaugurada en noviembre de 2008. Se ubica en una zona residencial exclusiva (Puerto Madero) y muy cerca de la Reserva Ecológica Costanera Sur; es de forma rectangular, entre las avenidas Elvira Rawson Dellepiane y Rosario Vera Peñaloza, y las calles Julieta Lanteri y Calabria. Se articula a un proyecto urbanístico de usos múltiples desarrollado por la firma GNV Group, que diseña un amplio complejo urbano de oficinas, conjuntos habitacionales, restaurantes, hoteles de cinco estrellas, supermercados, cines, gimnasios, canchas de tenis, helipuerto y el primer centro comercial de Puerto Madero. La plaza nace a partir de la donación que hace esta firma de parte de sus terrenos.

Por su parte, la historia de la Plaza España, también conocida como Parque España, se puede remontar a la primera mitad del siglo XIX, donde antes estuvieron ubicados mataderos. El espacio fue inaugurado como Plaza 
de los Inválidos hacia finales de 1871, hasta que una ordenanza municipal de abril de 1900 la denominó Plaza de España (Fotografía 2). A finales del siglo XIX una parte fue destinada a la cría de especies arbóreas en un vivero, el cual fue reemplazado por juegos infantiles desde 1950. Su funcionalidad histórica brinda un espacio de ocio y recreación para los vecinos de la zona, en un área que no es central, como el caso Lavalle, y tampoco representa el alto poder de la Plaza Madero Harbour, al estar próxima a barrios de clase media y media-baja e "infraestructuras de frontera", como la Estación de Tren Constitución, a la que arriban diariamente personas del área metropolitana sur y de la ciudad de La Plata. De forma triangular, se encuentra entre los barrios Constitución y Barracas, rodeada por la avenida Caseros Amancio Acorta y la calle Baigorri.

\section{Fotografía 2}

Plaza España hacia 1900

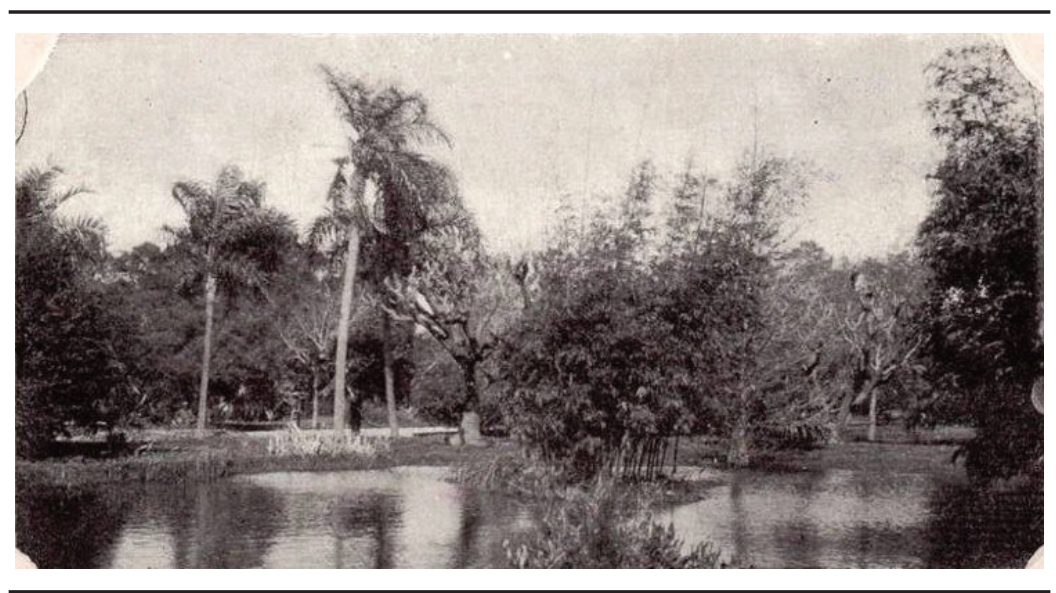

Fuente: https://es.wikipedia.org/wiki/Archivo:Parque_Espa\%C3\%B1a_(H.G._Olds, ca._1900).jpg (consultado el 25 de abril de 2019).

\section{Metodología}

La metodología planteada es propia de la investigación social cualitativa. El trabajo de campo y acopio de información se ha llevado a cabo a través del diario de campo, registros fotográficos y encuestas. La selección de las plazas objeto de estudio se basa en una práctica de investigación cualitativa: la caminata urbana. 
El diario de campo ha estado presente durante todo el trabajo de campo, haciéndose anotaciones sobre diseño, usos, usuarios, interacciones socioespaciales en cada plaza, etc. Esta información se ha completado con la toma de registros fotográficos. Ambos procedimientos permiten almacenar y retener información que la memoria no siempre es capaz de fijar de forma permanente. En el análisis y la redacción del trabajo, estos documentos son una fuente de información de gran valor.

La segunda herramienta es la encuesta de tipo exploratorio o encuesta flash (Hernández y Guerín, 2016), y tiene por objetivo reunir información básica sobre el uso y usuarios de la plaza. Se trata de un cuestionario de 10 preguntas, estructurado en tres temas: la distancia recorrida para llegar a la plaza desde el lugar de residencia; el tiempo de permanencia y frecuencia de uso; y la actividad realizada. Se añaden otras preguntas de cabecera como edad, sexo, actividad laboral y lugar de residencia. La información recogida permite completar las notas tomadas del diario de campo y la aportada en cada registro fotográfico. En total se aplicaron 90 encuestas, 30 en cada plaza.

La selección de las plazas es el resultado de una fase previa al trabajo de campo propiamente dicho: la caminata urbana, que consiste en proceder espacialmente de forma inductiva. Si se hace el símil con la forma en que se actúa cuando se quiere tener una visión amplia de un tema que interesa, pero del que poco se sabe, lo que se hace es una "búsqueda bibliográfica libre", viendo pasar un documento tras otro con curiosidad, pero sin un interés definido. La caminata urbana responde a esa forma de actuar, pero espacialmente. Seguramente en muchas ocasiones caminamos, deambulamos sin ser conscientes del recorrido y sus características, para después, probablemente de forma inconsciente, recuperar una imagen resultado de la experiencia espacial llena de olores, colores, escenas, elementos urbanos, personajes.

En la investigación social cualitativa no es muy frecuente esta técnica de trabajo para la selección de la unidad de análisis, aunque sus antecedentes inmediatos están en la corriente de la psicogeografía, "frontera donde convergen la psicología y la geografía, un modo de explicar el impacto del espacio urbano en el comportamiento" (Coverley, 2014). El acto que mejor responde a esta idea es la del flaneur, también errante, paseante, persona que deambula sin un destino preciso e incluso adentrándose por zonas que muestran la ciudad fea y desaliñada. Es "ir a la deriva" (Durán, 2011).

Así, una vez deambulado, caminado e ido a la deriva por la ciudad en diferentes horarios, se seleccionaron las plazas objeto de estudio y se definieron itinerarios de observación, teniendo en cuenta diferentes horarios y 
días de la semana. El trabajo de campo se desarrolló durante los meses de febrero y marzo de 2018, en horarios de mañana y tarde-noche de lunes a jueves, y los fines de semana en horarios de medio día. ${ }^{5}$ Con este ejercicio se identifican también diferentes dinámicas de uso en cada plaza, siendo posible decidir las franjas horarias más oportunas para realizar las encuestas.

\section{Las plazas, espacios de sociabilidad}

\section{Lavalle, una plaza central de usos múltiples y múltiples sociabilidades}

La Plaza Lavalle es la más grande de las analizadas al contar con tres sectores diferenciados. La densidad de usuarios es significativa debido en parte a su funcionalidad como un pasillo conector entre diferentes áreas donde son frecuentes los edificios oficiales y también los culturales ${ }^{6}$ (Fotografía 3). Cada espacio está identificado por su uso o contenido: en la zona norte se encuentra un parque infantil; en la zona central el referente es un árbol de raíz ancha, conocido como árbol jujeño, considerado patrimonio natural de la plaza; y en la parte sur se ubican casetas de venta de libros, una estación subterránea del metro y una pileta.

En general, los espacios son utilizados para descansar bajo la sombra de árboles situados en zonas ajardinadas delimitadas por borduras de obra con espaldares de presencia intermitente que cumplen la función de asientos (Fotografía 4). Un primer aspecto es la relación entre sociabilidad y espacios verdes, y particularmente las prácticas de uso que éstos potencian. ${ }^{7}$ Sus amplias zonas verdes alfombradas de césped son utilizadas para el descanso, favorecido por las sombras que proporcionan árboles de gran porte. Esto potencia la capacidad de los espacios para generar escenarios de permanencia, ya sea para "pasar el rato", consumir alimentos, leer, charlar, enamorar, relajarse, descansar, etc. Destacar esta potencialidad en el análisis de la sociabilidad es fundamental, más aún cuando la categoría espacio verde ocupa un lugar central en la planificación urbana. La necesidad de espacios verdes

${ }^{5}$ El trabajo de campo está relacionado con una estancia de investigación en el Instituto Gino Germani de la Universidad de Buenos Aires, durante el primer trimestre de 2018.

${ }^{6}$ Cámara Nacional de Apelaciones en lo Civil, Corte Suprema de Justicia, Secretaría Electoral, Registro Nacional de Reincidencia, Museo Nacional y Teatro Nacional Cervantes, entre otros edificios.

${ }^{7}$ La Plaza Lavalle podría servir para contrastar las plazas de cemento, cuya construcción dominó en el periodo de la dictadura. El diseño de éstas, también denominadas plazas secas o plazas grises, estaba pensado para controlar los comportamientos que se esperaban en dichos espacios (Romagnoli, 2006). 
y plazas es incluso una percepción que los vecinos de la ciudad demandan, como se constata en el estudio Percepciones sobre el barrio (Defensoría del Pueblo CABA, 2017), en el que, entre otras cosas, queda manifiesta la insatisfacción de los vecinos por la escasez de espacios verdes y las amplias distancias que separan a éstos del lugar de residencia. Según el informe citado, la cifra de espacios verdes es de $5.9 \mathrm{~m}^{2} /$ habitante, lejos de los 9 metros cuadrados recomendados por la OMS. ${ }^{8}$

La segunda variable de sociabilidad que se destaca tiene que ver con su diseño en relación con la movilidad urbana. La plaza se divide en tres espacios atravesados por dos vías principales en dirección occidente-oriente (vía Tucumán y vía Viamonte) (Fotografía 5). Estas fronteras internas, además de "compartimentar" en tres espacios la plaza, potencian su uso en relación con las rutas de buses, las líneas del metro subterráneo, los trayectos peatonales largos y las ciclorrutas.

\section{Fotografía 3}

Plaza Lavalle: edificios oficiales y culturales

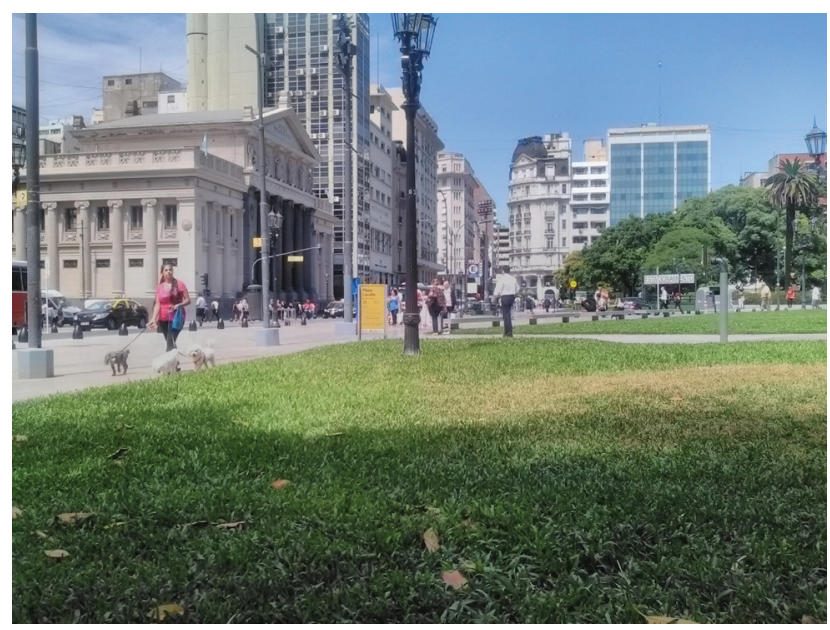

Fuente: Colección de Edward Leonardo Salamanca Ospina.

${ }^{8}$ Hay ciertas dudas sobre esta recomendación, incluso de que sea un pronunciamiento oficial de la OMS. Véase https://blogs.iadb.org/ciudadessostenibles/2012/06/28/la-ciudadeslatinoamericanas-poseen-suficiente-espacio-verde-publico-que-es-suficiente-existe-unminimo/ 


\section{Fotografía 4}

Plaza Lavalle: espacios para descansar

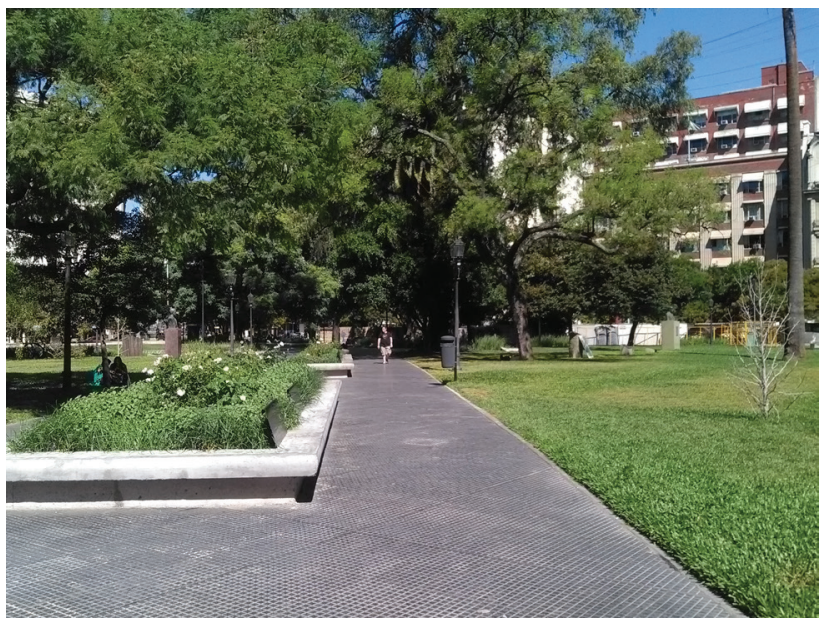

Fuente: Colección de Edward Leonardo Salamanca Ospina.

\section{Fotografía 5}

Plaza Lavalle: vías principales

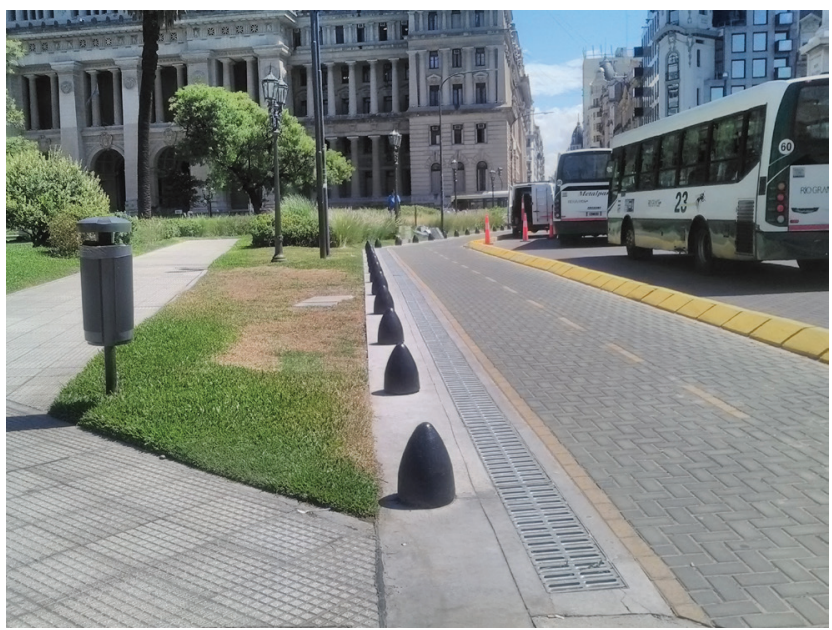

Fuente: Colección de Edward Leonardo Salamanca Ospina.

Estudios Demográficos y Urbanos, vol. 35, núm. 2 (104), mayo-agosto, 2020, pp. 517-556 http://dx.doi.org/10.24201/edu.v35i2.1880 
En la zona norte los corredores de conexión diferencian espacios exclusivamente peatonales; en este sentido, no solamente el diseño permite realizar "actividades pasivas" como descansar en las zonas verdes, sino que a la vez se articula a un uso más activo para caminar, pasear o desplazarse de un lugar a otro (Fotografía 6). La conexión de los espacios públicos con las formas de movilidad es vital para comprender las formas de apropiación del espacio. Así como los espacios verdes potencializan las relaciones sociales del estar, la conectividad caracteriza relaciones de uso más fugaces determinadas por el ir y venir y el uso pragmático de la ciudad. La relación explícita que tiene esta plaza con la movilidad permite que cotidianamente su uso tenga diferentes tipos de usuarias/os que buscan suplir necesidades sociales, como el ocio, la recreación, las compras, el acceso a lugares de trabajo, de educación, entre otras. En ese sentido, la movilidad y las prácticas de apropiación que la secundan potencian el uso diferencial de la ciudad (Blanco, Bosoer y Apaolaza, 2014; Di Virgilio, 2014) y pueden determinar incluso que las personas que lo usan no sean residentes cercanos a la plaza.

Un tercer aspecto tiene que ver con el papel que juega el equipamiento urbano como elemento potenciador de la sociabilidad en la plaza. En este sentido, el trabajo de campo permitió destacar equipamientos como las fuentes, que favorecen la presencia de habitantes de calle (a veces familias completas) que llegan hasta aquí a lavar su ropa y asearse, haciendo una apropiación funcional de este espacio para un uso de carácter doméstico (Fotografía 7). Un uso similar hacen de la fuente concebida como monumento a la memoria de las personas del Ballet Nacional fallecidas en un accidente aéreo en 1971. Así, la plaza no escapa a la visibilidad de la desigualdad urbana: aquellos espacios que permiten suplir necesidades inmediatas de determinados colectivos que dotan al espacio público con un significado doméstico para atender necesidades de hidratación e higiene. ${ }^{9}$ Lo anterior es un ejemplo de cómo el diseño no es una característica a priori que se sobrepone al uso que las comunidades hacen del espacio público; por el contrario, uso y diseño mantienen una relación conflictiva que depende del escenario económico y político en el que se tejen las relaciones de sociabilidad.

${ }^{9}$ La presencia de habitantes de calle, o más bien familias habitantes de calle, es permanente; esto se aprecia por la presencia de enseres (maletas con ropa y útiles de uso personal y colchones); aquí comen, beben, fuman y tienen cierta familiaridad con otras personas habituales en la plaza, como los vendedores ambulantes. Los niños de estas familias recorren en ocasiones la plaza pidiendo dinero como una actividad de diversión. La presencia de este colectivo es considerada por algunas/os usuarias/os como uno de sus problemas principales. 


\section{Fotografía 6}

Plaza Lavalle: zonas arborizadas

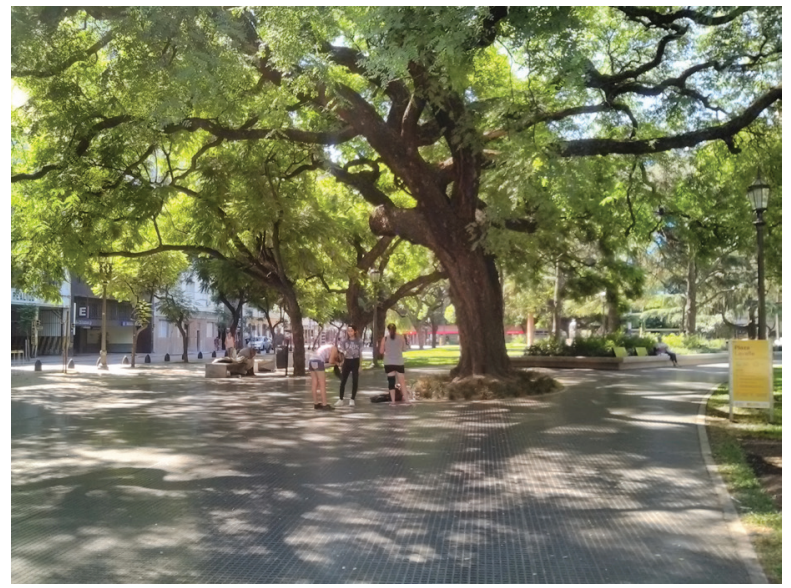

Fuente: Colección de Edward Leonardo Salamanca Ospina.

\section{Fotografía 7}

Plaza Lavalle: habitantes de calle

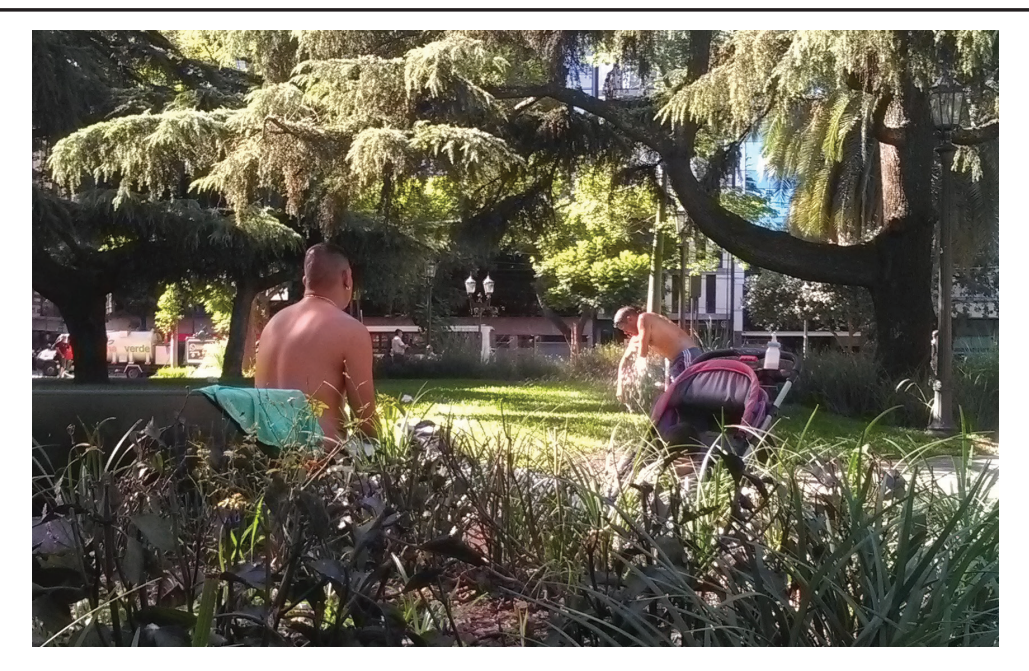

Fuente: Colección de Edward Leonardo Salamanca Ospina.

Estudios Demográficos y Urbanos, vol. 35, núm. 2 (104), mayo-agosto, 2020, pp. 517-556 http://dx.doi.org/10.24201/edu.v35i2.1880 
Un segundo equipamiento, el parque infantil, condiciona otro perfil de sus usuarias/os y las actividades realizadas: familias jóvenes o personas mayores que cuidan a la población infantil (posiblemente nietas/os) de manera relajada, por la seguridad que ofrece el mismo diseño de la instalación. Los parques infantiles son espacios que permiten resaltar diferentes tipos de sociabilidad por excelencia: niñas y niños encuentran un diseño propicio para compartir con extraños, funcionando como desahogo de la idea del "espacio público como enemigo", generando, al contrario, la sensación de seguridad (Segovia y Neira, 2005).

Un tercer equipamiento, cada vez más frecuente y que genera tanta sociabilidad como los parques infantiles, es el parque de perros, el cual propicia renovadas formas de sociabilidad en las ciudades contemporáneas en tanto facilita la interacción entre desconocidos desde la vivencia cotidiana de los dueños de mascotas (Rodríguez, 2014).

Otro equipamiento, el cuarto, tiene que ver con la presencia de estacionamientos de bicicletas públicas, que articulan la conectividad de la plaza con la movilidad urbana. Así, la zona central se identifica como un espacio más abierto y amplio por estar menos arborizado, aunque la presencia de césped es evidente, siendo un espacio de movilidad permanente ya que, junto al estacionamiento de bicicletas (Fotografía 8), se encuentra una parada del metro.

\section{Fotografía 8}

Plaza Lavalle: equipamientos e instalaciones (estacionamiento de bicicletas)

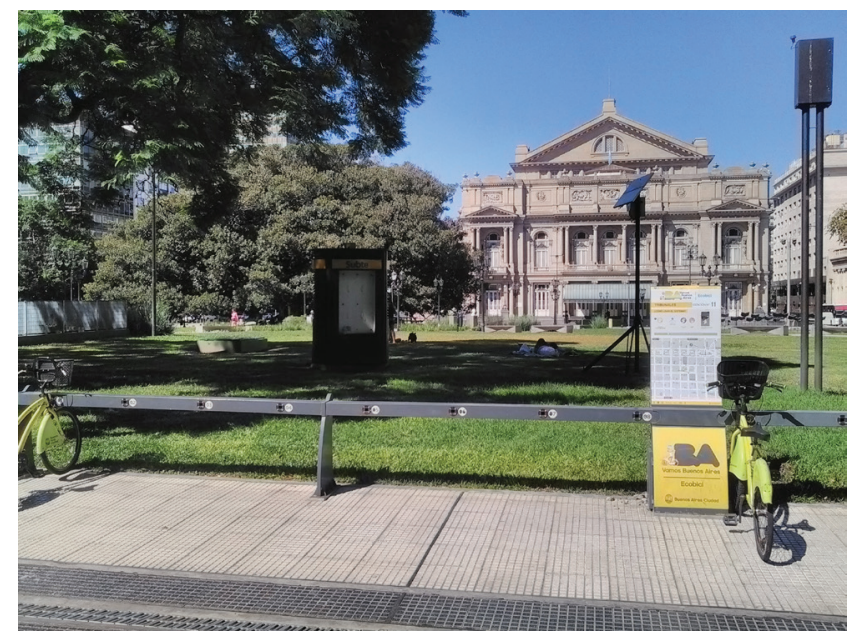

Fuente: Colección de Edward Leonardo Salamanca Ospina.

Estudios Demográficos y Urbanos, vol. 35, núm. 2 (104), mayo-agosto, 2020, pp. 517-556 http://dx.doi.org/10.24201/edu.v35i2.1880 
Y finalmente, está la instalación de venta de libros especializados en el área de derecho, posiblemente el único equipamiento de carácter comercial. Esta especialización se relaciona con la proximidad de las sedes de: la Cámara Nacional de Apelaciones en lo Civil, la Corte Suprema de Justicia, la Secretaría Electoral y el Registro Nacional de Reincidencia. Las casetas se identifican por estar decoradas con dibujos de grafitis que simulan estantes de libros y enriquecen visualmente el paisaje de la plaza (Fotografía 9). Su presencia asegura un momento de distracción para personas interesadas o curiosas, y es también una oportunidad para entablar una breve conversación con el vendedor o escuchar la opinión de otras personas que se detienen a conocer u ojear la oferta literaria.

\section{Fotografía 9}

Plaza Lavalle: casetas de libros

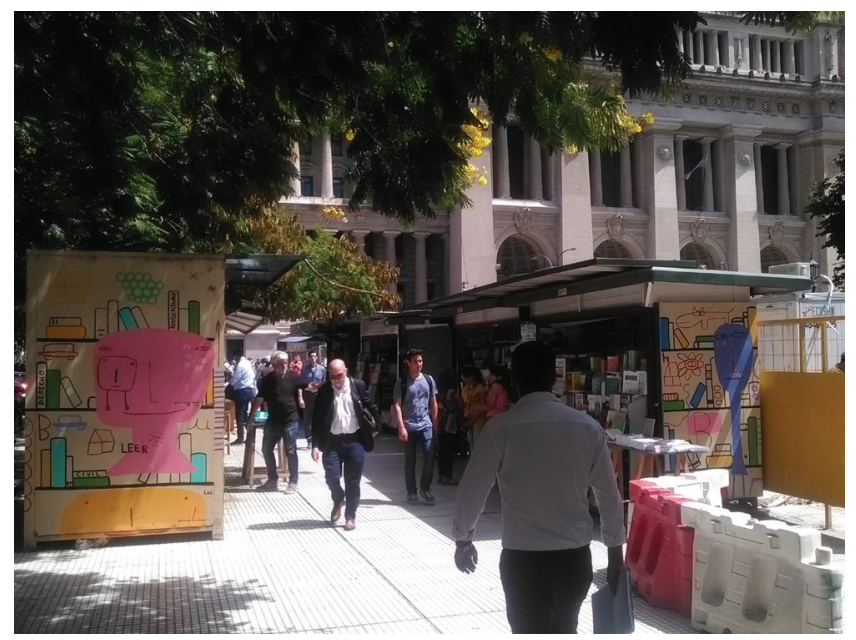

Fuente: Colección de Edward Leonardo Salamanca Ospina.

A pesar de la evidente apropiación del espacio por habitantes de calle, es frecuente ver durante la tarde a algunas personas reunidas en grupo para tomar algún alimento (Fotografía 10). Se trata así de un espacio compartido por usuarios más o menos ocasionales que comen o descansan junto a la pileta, y los de una presencia más habitual, como los habitantes de calle.

En la zona sur las actividades que prevalecen son: caminar, comer, descansar en el césped en grupo, aunque la observación continua amplió 
estos usos más frecuentes. Así, se constata que algunos movimientos sociales se dan cita en esta plaza, sobre todo en la esquina suroeste, próxima a la Corte Suprema de Justicia, que justificaría aquí estos actos reivindicativos (Fotografía 11).

\section{Fotografía 10}

Plaza Lavalle: usos y usuarios

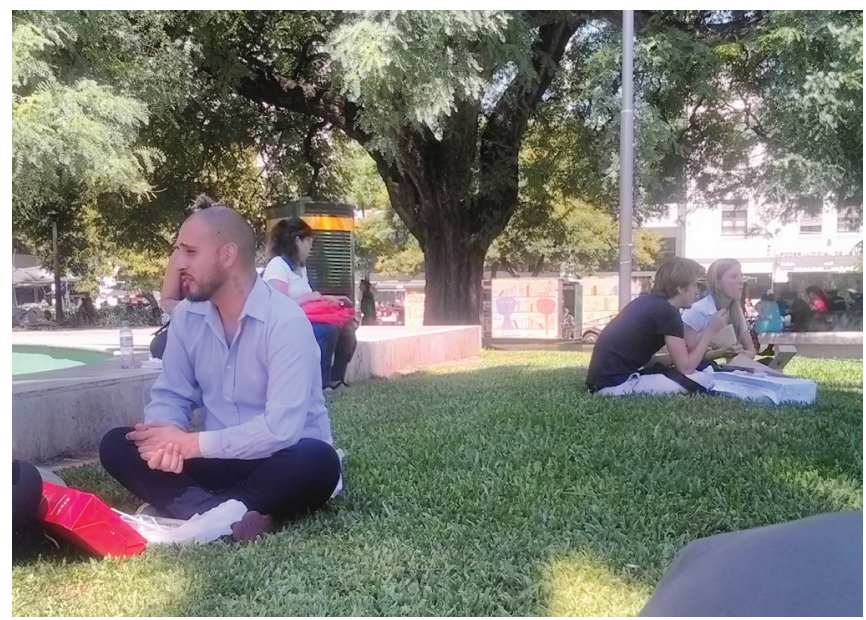

Fuente: Colección de Edward Leonardo Salamanca Ospina.

\section{Madero Harbour, elementos de sociabilidad interrumpida}

La Plaza Madero Harbour está integrada en un proyecto inmobiliario de usos mixtos que contempla la urbanización del Dique 1 de Puerto Madero. Forma parte de un complejo de espacios verdes urbanos y se localiza en el sector suroeste (Mapa 1), delimitada por las avenidas Rosario Vera Peñaloza (norte), Calabria (este), Elvira Rawon de Dellapiane (sur) y Julieta Lanteira (oeste), siendo estas dos últimas las que ponen a la plaza en contacto con edificios de uso residencial de alto poder adquisitivo, oficinas, hoteles y restaurantes de lujo. 


\section{Fotografía 11}

Plaza Lavalle: esquina sur-oeste, próxima a la Corte Suprema de Justicia

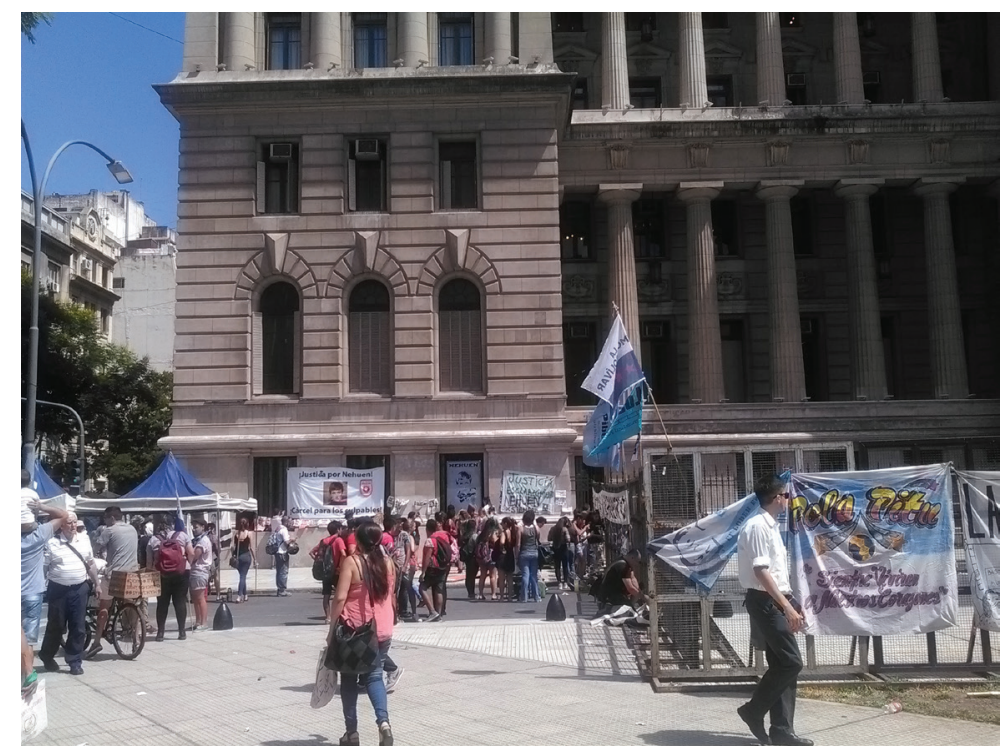

Fuente: Colección de Edward Leonardo Salamanca Ospina.

Desde su inauguración en 2008, una de sus características es que convive con la oferta de actividades de uso privado del complejo urbanístico desarrollado por la firma GNV Group. El espacio es un cuadrilátero con árboles frondosos, cuya sombra favorece el descanso y la permanencia en la plaza, facilitado a su vez por la presencia de bancos de madera sin espaldar dispuestos en los corredores de la plaza (Fotografía 12), y butacas en forma circular en las zonas de césped; además cuenta con un parque infantil y una zona dedicada a la memoria de Evita Perón.

En esta plaza los elementos de sociabilidad se definen por patrones asociados a la densidad de usuarias/os, que es mayor los fines de semana; por ello se define esta plaza como de sociabilidad interrumpida, ya que la oferta de actividades, visitas y tiempo de permanencia relacionada con ella está asegurada en esos días y en particular el domingo, estableciendo formas específicas de apropiación del espacio. Esto se explica en parte por ubicarse en una zona residencial, menos conectada a las líneas de transporte público y por lo tanto de accesibilidad menor; de manera que, al tener que recorrer 
distancias de hasta más 10 cuadras (con procedencias de al menos 19 barrios diferentes), las visitas se realizan en días de descanso y la permanencia es de varias horas, a veces de hasta cuatro o más. El domingo es el día de mayor interacción. Diversas actividades, como las deportivas (trotar, montar bicicleta, patinar, jugar con la pelota, hacer gimnasia), pasear la mascota, celebrar picnics, así como la presencia de familias e infantes, confieren al espacio un ritmo que muy bien puede ser un claro indicador de integración social (Ramírez, 2007; Treviño, 2013; Petzold, 2017; Gomes y Parente, 2018).

Las interacciones sociales se incrementan aún más con la presencia de un mercado de productos alimentarios cuya frecuencia está normalizada el fin de semana, es el "mercado de los domingos" (Fotografía 13), con un punto fijo de instalación al norte sobre la avenida Rosario Vera Peñaloza; lo forman unos siete puestos de productos alimentarios: verduras, alimentos dietéticos, carne, pescado, embutidos, quesos y panadería. Su pequeño tamaño contrasta con su alta capacidad para atraer personas con la intención de comprar o curiosear. En este sentido, el encuentro viene dado por la oferta de productos más allá del equipamiento con el que cuenta.

\section{Fotografía 12}

Plaza Madero Harbour: corredor

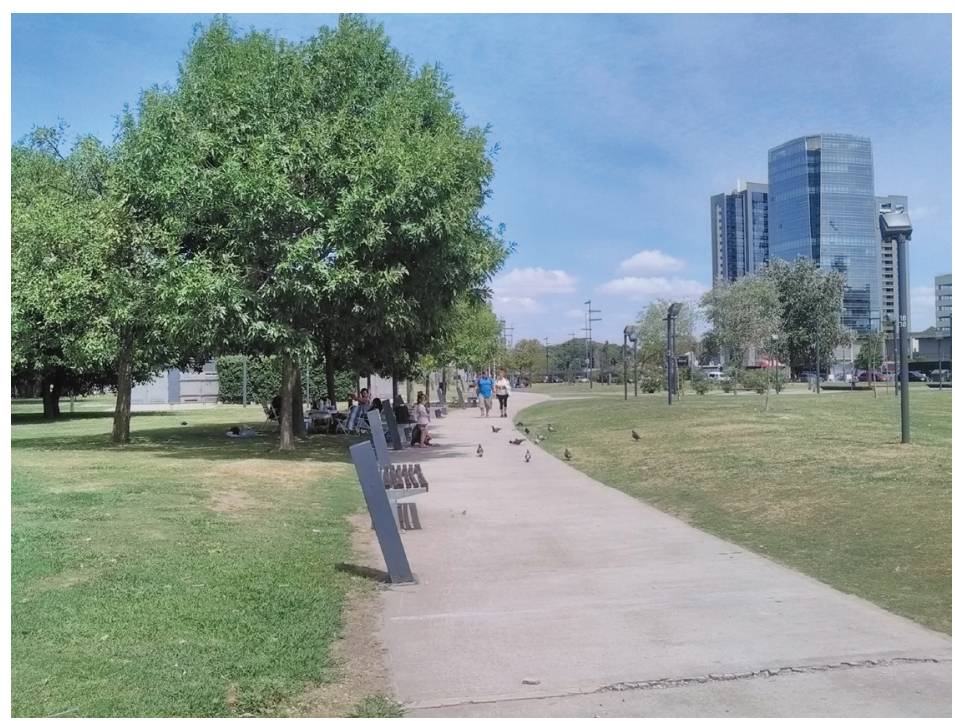

Fuente: Colección de Edward Leonardo Salamanca Ospina. 


\section{Fotografía 13}

Plaza Madero Harbour: mercado del domingo

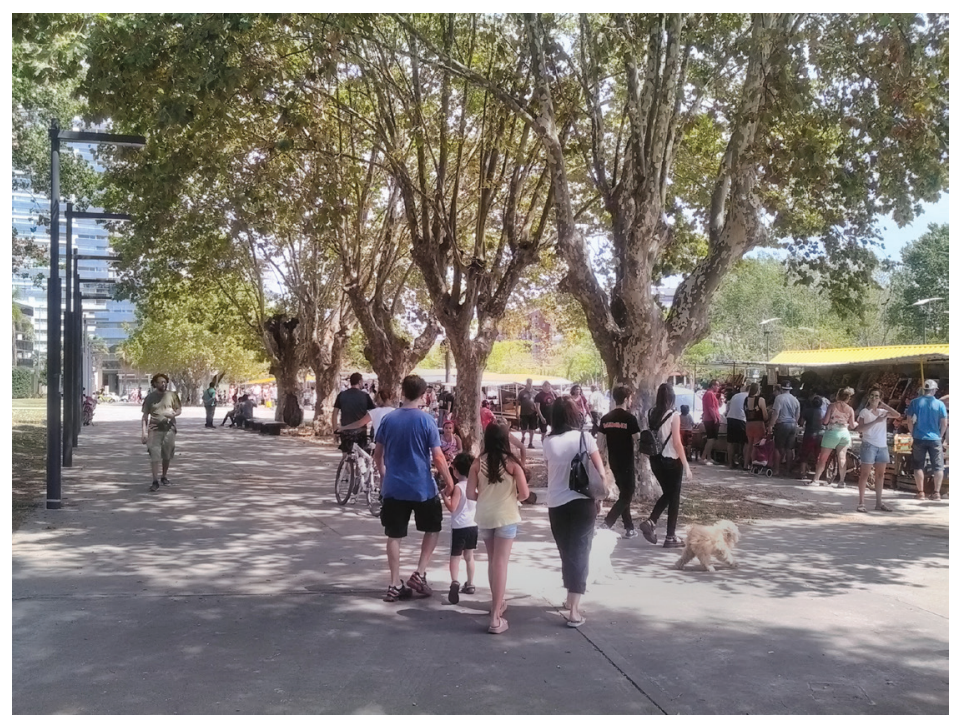

Fuente: Colección de Edward Leonardo Salamanca Ospina.

Observada en domingo, se puede decir que esta plaza es un escenario con pautas de uso y ocupación que pueden denominarse "adaptativas"; es decir, los usuarios se adaptan a su diseño físico y equipamiento para realizar actividades; o bien el espacio se presenta como un espacio abierto del que es posible hacer usos diferentes sin dificultades, impedimentos y/o barreras. Esto se advierte sobre todo en una actividad muy "dominguera" y familiar: el picnic, en el cual las personas en grupos familiares personalizan el espacio haciendo uso de sus propias sillas plegables y de mantas o toallas para recostarse en el césped y tomar el sol (Fotografía 14), como opciones fáciles ante la falta de mobiliario urbano adecuado para dicha actividad. Esto se observa en el lado este, donde la agrupación de árboles a modo de un pequeño bosque favorece la sombra y la celebración de una comida familiar. Esto permite afirmar que lo público favorece lo privado (Monteys, 2017). ${ }^{10}$

10 "La comida establece un vínculo automático e innegable entre la casa y la calle, entre lo privado y lo colectivo, y probablemente sea el mejor vehículo para hacerlo [...]. La ciudad suplanta el papel que la casa ha tenido tradicionalmente [donde] la comida es un acto social de una gran trascendencia" (Monteys, 2017, p. 92). 


\section{Fotografía 14}

Plaza Madero Harbour: picnic del domingo

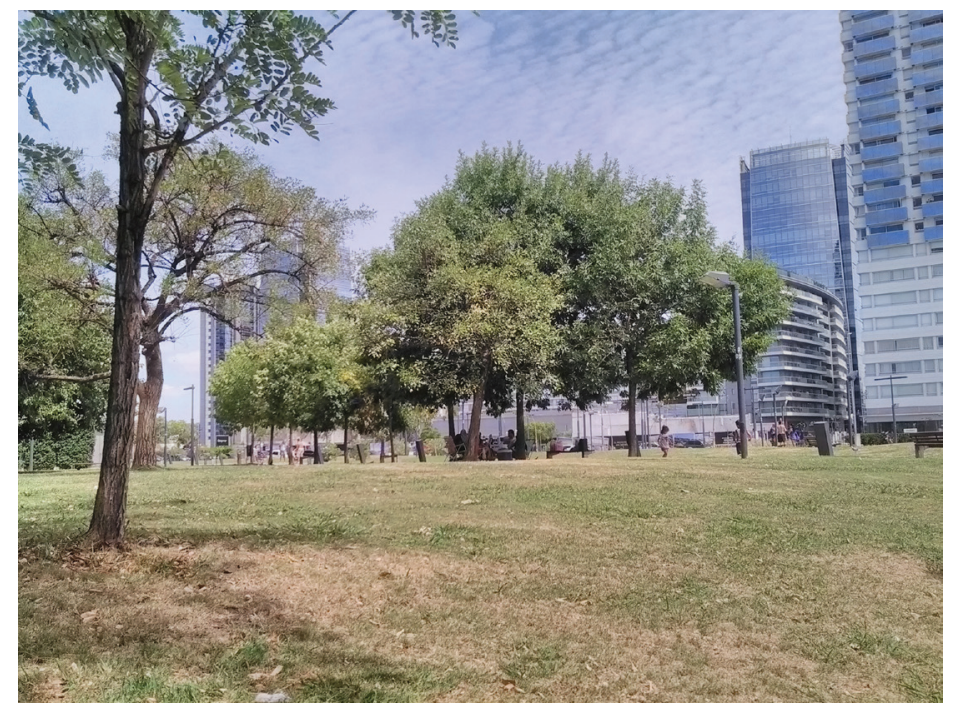

Fuente: Colección de Edward Leonardo Salamanca Ospina.

Este despliegue de actividades en domingo se interrumpe durante los demás días de la semana, ya que algunas de éstas, como la del mercado o los picnics, no se realizan, siendo la afluencia de personas también menor, aunque prevalece pasear solo o en compañía de la mascota, trotar o montar en bicicleta. Tales actividades se amplían con otra cada vez más frecuente y normalizada en muchos espacios públicos, incluida la calle: el almuerzo compartido en pequeños grupos de dos o tres personas, donde, como se ha señalado anteriormente, se manifiesta la permisividad de la ciudad para llevar lo privado a lo público.

Estas formas de sociabilidad plantean una dependencia obvia con el ritmo cotidiano y rutinario de la ciudad, lo cual está determinado por el sustrato material, es decir las formas de ciudad diseñadas para promover patrones de sociabilidad; por las prácticas urbanas que permiten observar las formas como son vividos y apropiados los lugares; y por las relaciones sociales que se tejen entre los ciudadanos (Thuillier, 2005). Siguiendo estas pautas, en esta plaza habría que preguntarse qué pasaría, por ejemplo, si la presencia de espacios verdes y masa arbórea fuera menor, ¿sería habitual 
encontrar familias los domingos?, ¿las familias seguirían recorriendo amplias distancias para permanecer en la plaza?, ¿sin el mercado, la densidad de usuarios sería la misma? Las respuestas, que pueden ser diversas, pasan necesariamente por la reflexión de las relaciones conflictuales entre diseño y uso. En este sentido, la simple presencia de equipamientos como parques infantiles, mobiliario de permanencia, o aparatos de gimnasio al aire libre, no determinan necesariamente su uso, sino que éste se articula a diferentes variables como la conexión al transporte público, los ritmos de la vida cotidiana marcados por horarios fijos y normados, y la calidad de los espacios verdes.

\section{Plaza España, formas de sociabilidad sin límites}

La Plaza España tiene forma triangular (Mapa 1) y se ubica en el barrio Barracas (Comuna 4) y en el límite con Constitución (Comuna 1). Está rodeada de urbanizaciones y una considerable oferta de hoteles-pensión en los que se suele encontrar a poblaciones vulnerables, de condición socioeconómica baja y/o en situación de desventaja socioeconómica (Boy, Marcus y Perelman, 2015). Al sur, sobre la calle Amancio Alcorta, se ubica el Hospital Rawson y una residencia de personas mayores con el mismo nombre. En el mobiliario urbano predominan bancas de cemento y sendas internas que la comunican desde su centro hasta las calles que la circundan. Predominan árboles de abundante follaje que proporcionan grandes sombras. Algunas actividades suelen presentarse en horas de la tarde, sobre todo los chicos juegan futbol sobre el césped, aunque dominan actividades menos aeróbicas, como sentarse, comer y pasear mascotas (Fotografía 15).

Cuenta con varios microespacios en su interior: dos parques infantiles; un área con mobiliario de gimnasio; mesas fijas de cemento con sobremesa de tablero de ajedrez, rodeadas de asientos, y usadas más para comer y charlar que para jugar (Fotografía 16). El mobiliario urbano de permanencia se completa con las mantas que llevan las mismas personas visitantes, las cuales garantizan comodidad, familiaridad y permanencia prolongada. Es una forma frecuente de sociabilidad y de apropiación del espacio; una ocupación no entra en conflicto con la norma ni con las valoraciones de otros viandantes: está comúnmente aceptada. 


\section{Fotografía 15}

Plaza España: corredor central

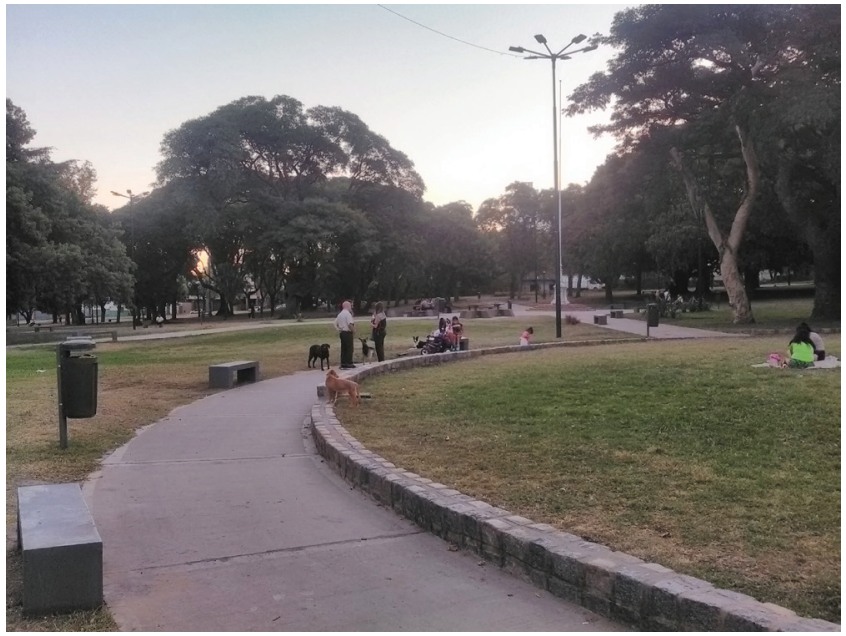

Fuente: Colección de Edward Leonardo Salamanca Ospina.

\section{Fotografía 16}

Plaza España: personas sentadas en torno a las mesas de ajedrez

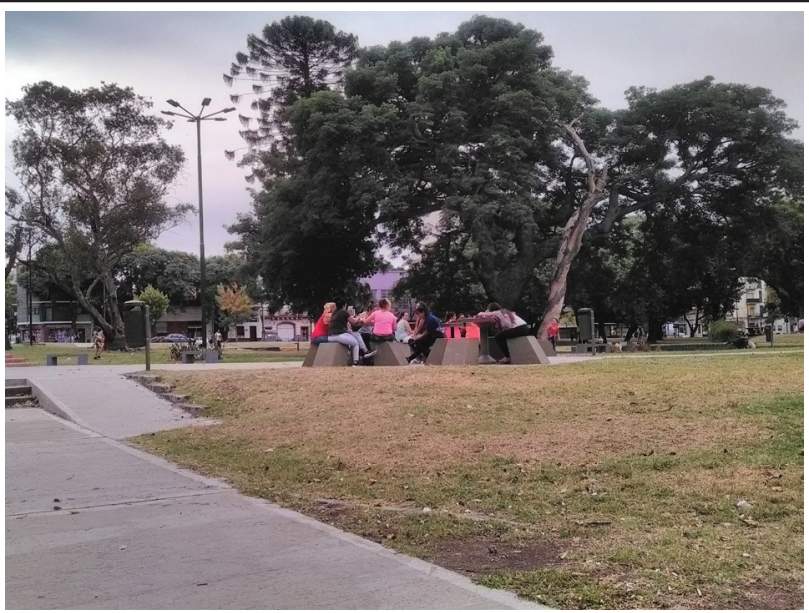

Fuente: Colección de Edward Leonardo Salamanca Ospina.

Estudios Demográficos y Urbanos, vol. 35, núm. 2 (104), mayo-agosto, 2020, pp. 517-556 http://dx.doi.org/10.24201/edu.v35i2.1880 
En algunos horarios, el encuentro lo protagonizan sobre todo hombres que consumen sustancias psicoactivas y alcohol en zonas específicas de la plaza. Entre semana y en la franja horaria del mediodía, la densidad de usuarios es menor y es cuando algunos habitantes de calle se reúnen en las zonas más esquinadas, con carros de mercado llenos de cobijas y enseres personales para consumir alcohol, práctica que termina siendo un catalizador de sociabilidad y apropiación del espacio. El consumo de alcohol es frecuente en diferentes puntos de la plaza, acompañado con música, lo cual a veces es una "barrera" para transitar por estas zonas. También es frecuente que grupos de "moteros" 11 se reúnan en zonas específicas a fumar hierba.

Estas escenas ilustran diferentes esferas de sociabilidad no siempre permitidas en todos los espacios públicos, pero aquí parecen no tener "límites" y, por el contrario, forman parte de rituales de visibilización garantizando el sentido de pertenencia al lugar (Ortiz, 2006; Fabre y Egea, 2014); remiten además a una apropiación diferencial del espacio según el perfil de los usuarios. Las áreas que circundan los parques infantiles están apropiadas por familias; la parte central y la zona nororiental, sobre la avenida Amancio Alcorta, congregan principalmente a los adultos que consumen alcohol y algunos habitantes de calle; y en la parte occidental se suelen reunir grupos de jóvenes y/o moteros a consumir hierba.

La dinámica descrita varía los fines de semana, cuando las actividades están más relacionadas con el ocio familiar, como organización de picnics, tomar mate e incluso realización de asados (Fotografía 17); junto a dichas actividades se desarrollan otras, también comunes, como las de jóvenes que juegan al futbol, realizan "murgas" 12 o ensayan batucadas. Así, la pluralidad de actividades en un solo espacio es significativa.

Los asados son un buen ejemplo de cómo un lugar público se (re)convierte en un espacio familiar con uno de los actos sociales más trascendentales, el momento de la comida (Fotografía 18) (Monteys, 2017). Un extracto del diario de campo ilustra este momento de sociabilidad.

En la parte de las mesas de ajedrez una familia prepara un asado, amenizado con música tradicional argentina, que sale de un equipo de sonido que llevó la familia. La comida del asado está preparada en dos mesas para ponerla en la parrilla. También tienen elementos de aseo para limpiar el lugar. Dos hombres están encargados del fuego, dos mujeres descansan sentadas y dos niños peque-

${ }^{11}$ Personas aficionadas a la conducción de motocicletas de gran cilindrada y que cotidianamente las usan como medio de transporte (N. del E.).

${ }^{12}$ Género musical característico de algunos países de América Latina, con expresión preferentemente en la calle y en otros espacios públicos (N. del E.). 
ños juegan a la pelota. La familia se ha apropiado de cuatro mesas: dos están ocupadas por los alimentos y las bebidas del asado, una está para descansar y hablar, y otra cumple con la función de servir de base del equipo de sonido. Todas las mesas disponen de un mantel; se simula al máximo un ambiente familiar [Diario de campo, 04/03/2018].

\section{Fotografía 17}

Plaza España: el picnic, un acto social privado hecho público

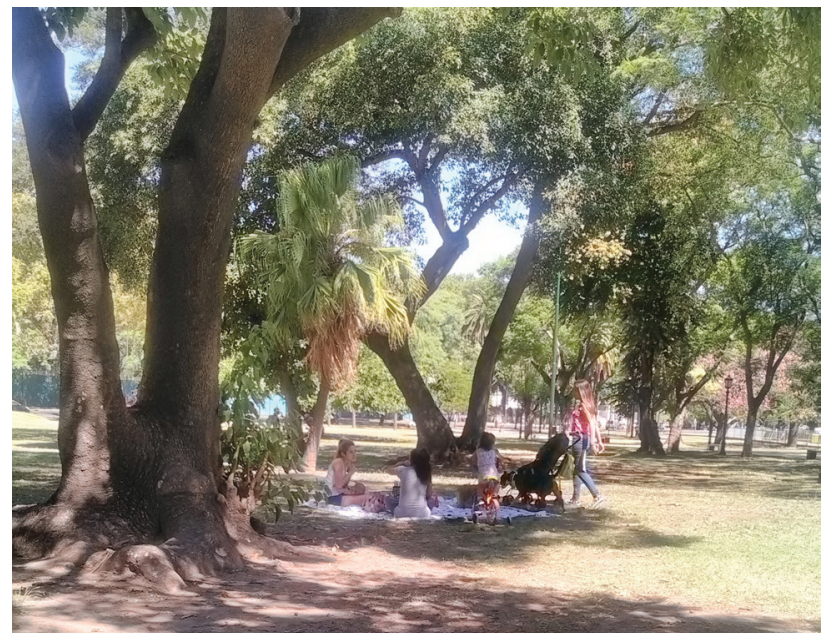

Fuente: Colección de Edward Leonardo Salamanca Ospina.

\section{Elementos transversales y particulares que definen la sociabilidad en las plazas}

El primero de estos elementos, que atraviesa cualquier espacio público y en concreto las plazas analizadas, es la permanencia, la cual es un indicador que permite medir también su calidad. Para que tenga lugar el hecho de estar y del encuentro, las características de las plazas tienen que estimular el tiempo de permanencia para que se produzcan las múltiples interacciones que caracterizan la sociabilidad. Lo observado reafirma lo avanzado en otros estudios (Del Valle, 2004; Núñez e Higueras, 2018), que insisten en la importancia del mobiliario para la permanencia, a lo que se suma la proximidad a la plaza y las actividades que se puedan realizar (Gehl, 2006). 


\section{Fotografía 18}

Plaza España: el asado

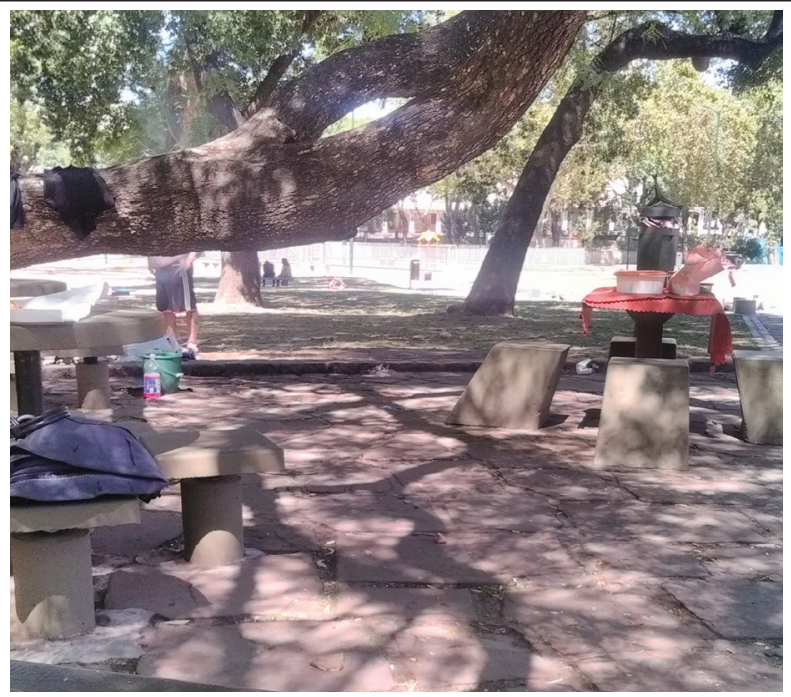

Fuente: Colección de Edward Leonardo Salamanca Ospina.

En el caso de las plazas objeto de estudio, y sin querer valorar unos equipamientos sobre otros, las amplias zonas de césped completan la presencia de bancos en su función de estar y permanecer; e incluso el uso del césped, más allá de la función exclusiva de embellecimiento en muchos parques y plazas, permite realizar actividades, buscando la comodidad, confortabilidad y familiaridad con el uso particular de toallas o mantas: dormitar, charlar, leer, escuchar música, o comer, como parte de la jornada de trabajo o como una actividad lúdica y "dominguera" a modo de picnic o asado. En este sentido, se puede asegurar que existe una clara relación entre los espacios verdes y la sociabilidad. Aunque los conjuntos de masa arbórea y el tipo de césped y jardines varían de forma significativa de una a otra plaza, su diseño no podría explicarse sin la alta presencia y valor que los usuarios les dan para realizar sus actividades, posiblemente más que a los mismos bancos de otros parques diseñados en la idea del orden social, el embellecimiento y la contemplación, como los diseñados entre finales del siglo XIX y comienzos del XX (Salazar, 2007; Arango, 2012).

Otros equipamientos son los microespacios que generan los parques infantiles, los parques de perros o los gimnasios, que muy bien se pueden 
asimilar al concepto de sociolugares de Páramo (2011), como claros generadores de sociabilidad entre desconocidos (o no) que, de manera fortuita o programada, comparten un mismo espacio y tipo de actividad. Estos espacios son fundamentales para impulsar el uso de las plazas, hasta el punto de que, si se llegaran a inhabilitar éstas, perderían parte de su potencial de sociabilidad: es indudable la facilidad con la que se puede compartir una conversación entre personas desconocidas mientras se observa el divertimento de hijas e hijos en un espacio infantil.

En cuanto a la proximidad, está relacionada con el concepto de espacio público de éxito (Pérez, 2004), en el sentido de que debe existir una relación entre afluencia de visitantes y tiempo de permanencia con la distancia recorrida para llegar a la plaza; sin embargo, esta tercera variable no necesariamente condiciona las otras dos. Así, en el caso de este estudio, a la pregunta: ¿a cuántas cuadras de la plaza está su vivienda?, la mayoría de las personas presentes en las plazas Lavalle y Madero Harbour contestaron haber recorrido más de diez cuadras (Gráfica 1), de manera que las motivaciones para llegar hasta aquí y permanecer hasta cuatro horas o más deben superar el inconveniente de la distancia. Esto contrasta con las personas que acuden a la Plaza España, donde el recorrido apenas supera las cinco cuadras (Gráfica 2).

\section{Gráfica 1}

Distancia en cuadras a la plaza

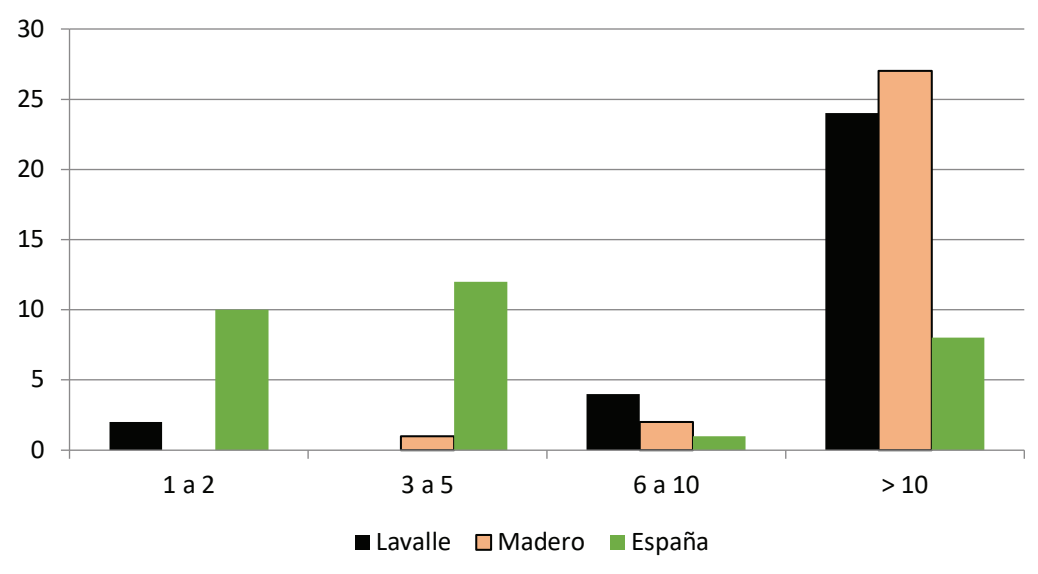

Fuente: Elaboración propia. 


\section{Gráfica 2}

Tiempo de permanencia en la plaza

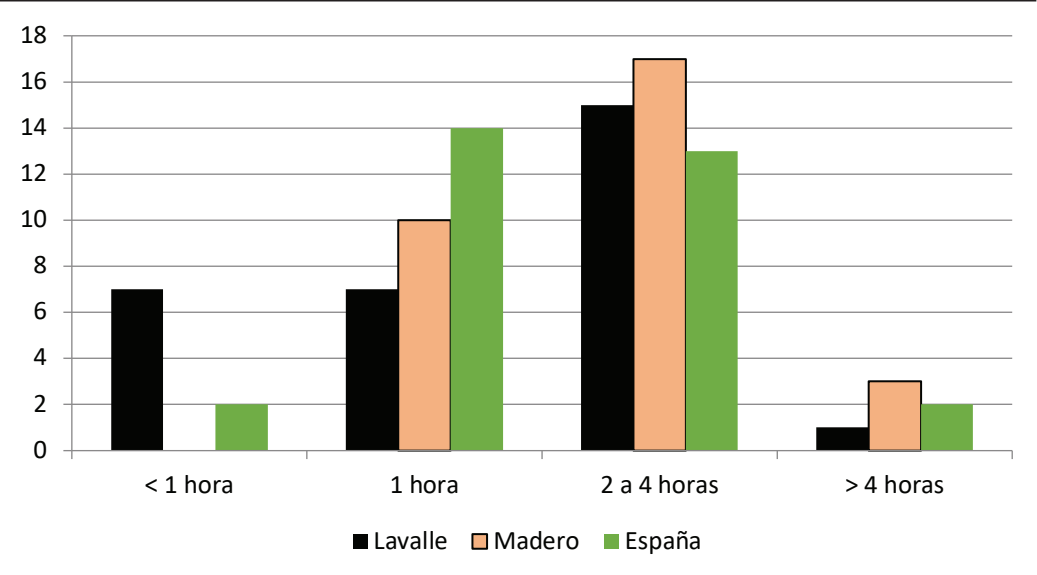

Fuente: Elaboración propia.

Seguramente es la proximidad lo que explique que las personas que frecuenten la Plaza España permanezcan en la misma un tiempo menor, pero con visitas más frecuentes a lo largo de la semana (Gráfica 3), mientras que en las que el recorrido es largo, el tiempo de permanencia es mayor y menor la frecuencia con la que se visita; es decir, su uso forma parte de la cotidianidad, frente a las que después de un mayor recorrido entienden el "estar" como algo menos fugaz. En cualquier caso, se trata de visitas en horario de tarde, aspecto que no estaría relacionado con la proximidad ni con el tiempo de permanencia (Gráfica 4). Tanto la frecuencia "dominguera" -asimilada a la respuesta de "un día a la semana"- como la diaria, indican que las plazas son espacios de interés para la ciudadanía, escenarios de sociabilidad que forman parte de prácticas cotidianas.

En relación con las actividades, éstas generan sociabilidad en cuanto justifican la visita y permiten interaccionar compartiendo las mismas "cosas que hacer". Las actividades realizadas son también una forma de apropiación y pertenencia, de interaccionar con otras personas. Estar entretenido en un lugar concebido como de ocio es fundamental para su uso y éxito. En algunos espacios de estas características hay actividades programadas que una persona puede esperar encontrarse, pero no sería éste el caso de las plazas estudiadas, salvo algunas actividades de carácter comercial, como el "mercado del domingo" (Plaza Madero Harbour) o la venta de libros (Plaza 
Lavalle). De hecho, ante la pregunta: ¿conoce alguna actividad deportiva, cultural o recreativa que realice el gobierno local, el municipio, los vecinos?, la respuesta más frecuente entre las personas entrevistadas es "no". Y, por el contrario, no dejan de detallar actividades cuando se les pregunta: ¿qué actividades le gustaría que se hiciesen en la plaza?; las propuestas son ricas y variadas: actividades para la población infantil, para la población mayor, cuentacuentos, actividades culturales, baile, gimnasia, yoga, teatro, zumba, atletismo, festivales de música folklórica, etcétera.

\section{Gráfica 3}

Frecuencia de visitas

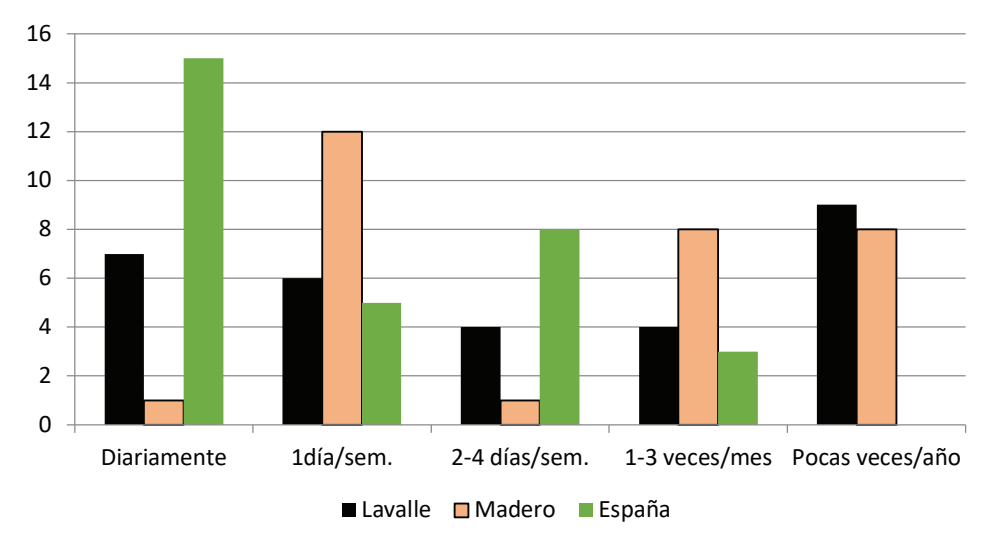

Fuente: Elaboración propia.

No obstante, la observación realizada permite interpretar el uso del espacio, aun sin esta diversidad de actividades programadas, como un espacio de uso libre de acuerdo con las posibilidades que el mismo ofrece y la normativa de uso acordada: desde la realización de un asado hasta la higiene personal, pasando por el juego infantil, el paseo acompañado de la mascota, ejercicio físico, compartir una cerveza, charlar, leer, acudir a un mercado, o la posibilidad de comprar libros... Son muchas de las actividades de ocio y recreo casi "(auto)proporcionadas". Las personas van porque saben que allí pueden estar entretenidas y pueden descansar. 


\section{Gráfico 4}

Franja horaria de uso

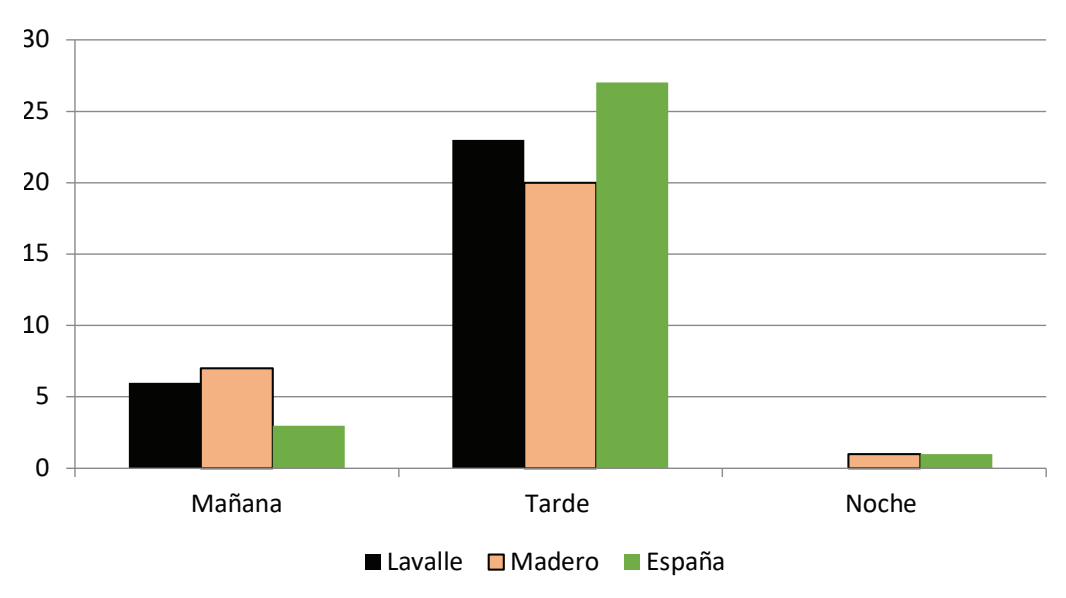

Fuente: Elaboración propia.

\section{Conclusiones}

El estudio permite reivindicar y conocer los espacios públicos, y en concreto las plazas, como lugares de convivencia y de sociabilidad frente a la idea de la crisis del espacio público, vinculada a los procesos de privatización. La crisis del espacio público como un concepto analítico del medio urbano se vincula al declive de la esfera pública (Habermas, 1981; Sennett, 2002), pero aquí la interpretación lleva a abrazar y recuperar de nuevo la idea de Kropotkin planteada al principio: la sociabilidad como base para sobrevivir y como un don de las sociedades más desarrolladas socialmente, valga la redundancia. Por otro lado, las prácticas cotidianas llevadas a cabo en las plazas hacen que el encuentro frecuente con una persona desconocida la convierta en alguien conocida, de la que "nos suena su cara", y esto también genera confianza y afectividad con el lugar (Gehl, 2006).

En las plazas estudiadas se ha visto que son múltiples los elementos que definen la sociabilidad. Éstos tienen que ver con el diseño y la amplia oferta de espacios verdes y masas arbóreas que proveen de amables zonas sombreadas, equipamientos de usos determinados como parques infantiles, para perros y gimnasios. Igualmente, la sociabilidad -los encuentros- está potenciada por actividades comerciales como el "mercado del domingo" en 
Plaza Madero Harbour, o la venta de libros en Plaza Lavalle; o por prácticas familiares privadas hechas públicas como una comida (picnic o asado) en Plaza España; por ensayos de batucadas; consumo de alcohol; o prácticas de higiene de los habitantes de calle.

El análisis realizado permite avanzar cuatro planteamientos teóricos sobre la sociabilidad de los espacios públicos. En primer lugar, los espacios públicos, y en específico las plazas, suelen valorarse o estar ancladas a la denominación de espacios verdes en algunos informes institucionales. Esto se traduce en una proyección del espacio público basada en la arborización, tipos de césped, flora y trazado de plazas (centrado en un paisaje de jardines y mobiliario que el diseño busca resaltar tanto en su estética como en su uso).

En segundo lugar, la observación permite reforzar la crítica de algunos planteamientos que, desde las políticas públicas, evalúan el uso y la calidad de los espacios públicos, considerando como uno de los indicadores su proximidad al lugar de residencia. Así, siguiendo la información recolectada en las encuestas, este es un criterio que solamente puede favorecer el análisis de la Plaza España; para la Plaza Madero Harbour y la Plaza Lavalle el criterio de cercanía no explica la afluencia de usuarios desde lugares distantes.

En tercer lugar, está la observación de escenarios de sociabilidad de grupos vulnerables, específicamente los habitantes de calle. Los lugares de ocio y uso colectivo "cubren" necesidades básicas como comida y agua, y un lugar donde estar y donde cobijarse (Medeiros, 2016). Algunos parques de la ciudad y plazas están amueblados con sofás, sillas y colchones, donde habría que ampliar la denominación de habitante de calle a familia de calle.

En cuarto lugar, fue recurrente relacionar el uso de las plazas con las necesidades de ocio infantil; es decir, su dinámica tiene una alta dependencia de la oferta de equipamiento para este colectivo. Las plazas son vividas en gran medida por familias, por lo que impulsan las prácticas de sociabilidad que éstas realizan en términos del cuidado que ameritan. La expresión "estar con los chicos" lleva a pensar en estos espacios como lugares predilectos para que las familias e infantes convivan; además, a pesar de que las plazas observadas cuentan con un equipamiento de parques infantiles de calidad, las sugerencias de las personas encuestadas señalan la falta de actividades para el colectivo infantil; casi se puede hablar de una percepción infantilizada de las plazas por parte de los usuarios mayores.

Para finalizar, y partiendo del trabajo de campo, se hace evidente que las plazas son espacios donde priman los encuentros de larga duración y/o de cotidianidad. Así, se han identificado bajo el potencial de configurarse 
en lugares de larga espera, algo que puede ir en contra de las dinámicas de consumo pragmático de los espacios de muchas ciudades. Se destaca de esta forma que los espacios públicos en general, y las plazas en particular, pueden propiciar escenarios de tiempo lento y otras dinámicas que los caracterizan como espacios de sociabilidad por excelencia.

En general, las plazas plantean escenarios de encuentros fortuitos, donde las personas realizan actividades recreativas, de larga espera y placenteras: descansar, pasear, charlar, caminar, "salir con los chicos". Todas ellas hacen de las plazas espacios de esparcimiento, ocio y disfrute del tiempo libre.

La sociabilidad sólo existe donde nos encontramos con otras personas o existe la posibilidad del encuentro, del roce, la mirada o la breve conversación que nos hace iguales con personas desconocidas, y esto permite hablar de sociabilidad horizontal (Lépore, 2012).

\section{Bibliografía}

Andrade, L., Jayme, J. y Almeida, R. (2009). Espaços públicos: novas sociabilidades, novos controles. Cadernos Metrópole, 21(1), 131-153. Recuperado de https://revistas.pucsp.br/index.php/metropole/article/ view/5959

Arango, S. (2012). Ciudad y arquitectura. Seis generaciones que construyeron la América Latina moderna. Ciudad de México: Fondo de Cultura Económica.

Ayala, E. (2015). La apropiación y modos de ocupación del espacio público.

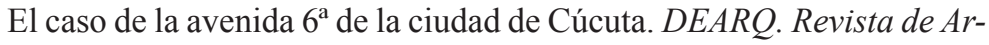
quitectura, 17, 74-85. Recuperado de http://www.redalyc.org/articulo. oa? id=341645612006

Barbosa, M. y Pérez, L. (1998). Los viejos de la plazoleta del Rosario: uso y apropiación del espacio público. Bogotá, Colombia: Observatorio de Cultura Urbana, Instituto Distrital de Cultura y Turismo.

Barros, M. y Virgilio, H. (2003) Praças: espaços verdes na cidade de Londrina. Geografia, 12(1), 533-544. Recuperado de http://www.uel.br/projetos/ atlasrml/publicacoes/periodicos/6713-24456-1-PB_londrina.pdf

Berjman, S. (1998) Plazas y parques de Buenos Aires: la obra de los paisajistas franceses (1860-1930). Buenos Aires, Argentina: Fondo de Cultura Económica.

Berneth, L. (2016). Securonormatividad. La sociabilidad urbana vista a través de las prácticas de la vigilancia cotidiana. URVIO. Revista Latinoa- 
mericana de Seguridad, 18, 104-123. Recuperado de https://revistas. flacsoandes.edu.ec/urvio/article/view/1792/1466

Blanco, J., Bosoer, L. y Apaolaza, R. (2014). Movilidad, apropiación y uso del territorio: una aproximación a partir del caso de Buenos Aires. Scripta Nova. Revista Electrónica de Geografía y Ciencias Sociales, 18 (493/06), 1-17. Recuperado de http://revistes.ub.edu/index.php/ ScriptaNova/article/view/14977/18345

Boy, M. (2018). El otro espacio público en los estudios urbanos de la Argentina actual: el género y las sexualidades también construyen ciudad. Quid 16. Revista del Área de Estudios Urbanos del Instituto de Investigaciones Gino Germani, 9, 153-167. Recuperado de https://dialnet. unirioja.es/servlet/articulo?codigo $=6566128$

Boy, M., Marcús, J. y Perelman, M. (2015). La ciudad y el encuentro de la diferencia. Adultos que viven en la calle y mujeres que habitan en hoteles-pensión. Ciudad de Buenos Aires, 2007-2011. Estudios Demográficos y Urbanos, 30(2), 369-404. Recuperado de https:// estudiosdemograficosyurbanos.colmex.mx/index.php/edu/article/ view/1478/1471

Brandis, D. y Del Río, I. (2016). Paisaje y espacio público urbano. El deterioro de las plazas del centro histórico madrileño (1945-2015). Cuadernos Geográficos, 55(2), 238-263. Recuperado de https://www.redalyc. org/articulo.oa?id=17149048011

Carrasco, D. (2011). Espacio público y ciudadanía. Nuevos desafíos para la agenda de desarrollo en Chile. Polis. Revista de la Universidad Bolivariana, 10(30), 19-43. Recuperado de http://dx.doi.org/10.4067/ S0718-65682011000300002

Carrión, F. (ed.). (2001). Los centros históricos en América Latina. Quito, Ecuador: UNESCO / BID / Ministerio de Cultura y Comunicación.

Casseti, F. y Lietti, R. (1995). La piazza televisiva. En M. Vitale y D. Scafoglio (coords.), La piazza nella storia: eventi, liturgie, rapresentazioni. Italia: Edizioni Scientifiche Italiane.

Chapman, W. (2015). El concepto de sociabilidad como referente de análisis histórico. Revista de Investigación y Desarrollo. Revista Latinoamericana de Ciencias Sociales y Desarrollo Humano, 13(1), 11-33. Recuperado de http://rcientificas.uninorte.edu.co/index.php/ investigacion/article/view/6040/7152

Coverley, M. (2014). Psicogeografía. Madrid, España: Carpe Noctem.

Defensoría del Pueblo CABA. (2017). Informe del estudio percepciones sobre el barrio. Buenos Aires: Defensoría del Pueblo CABA. 
Delgadillo, V. (2011). Patrimonio histórico y tugurios. Las políticas habitacionales y de recuperación de los centros históricos de Buenos Aires, Ciudad de México y Quito. Ciudad de México: Universidad Autónoma de la Ciudad de México.

Del Valle, T. (2004). Identidad y cambio urbano en Tolosa (Gipuzkoa). Una reflexión desde la antropología social. Kobie. Antropología Cultural, 11, 5-30. Recuperado de https://dialnet.unirioja.es/servlet/ articulo? codigo $=2015877$

Di Virgilio, M. (2014). Diferencias sociales en los procesos de movilidad residencial intraurbana en el Área Metropolitana de Buenos Aires (Argentina). Quivera, 16(1), 11-37. Recuperado de https://ri.conicet.gov. ar/handle/11336/35531

Durán, L. (2011). Miradas urbanas sobre el espacio público: el flâneur, la deriva y la etnografía de lo urbano. Reflexiones, 90(2), 137-144. Recuperado de https://revistas.ucr.ac.cr/index.php/reflexiones/article/ view/1466

Fabre, D. A. y Egea, C. (2014). Identidad, mito y rito en los no-lugares. Los jóvenes, alcohol y espacio público en Granada. En D. Sánchez González y L. A. Domínguez Moreno (coords.), Identidad y espacio público. Ampliando ámbitos y prácticas (pp. 169-194). Barcelona, España: Gedisa.

Finol, J. E. (2005). Globalización, espacio y ritualización: de la plaza pública al mall. Espacio Abierto, 14(4), 573-588. Recuperado de http:// www.redalyc.org/articulo.oa?id=12214404

Frehse, F. (2013). Os tempos (diferentes) do uso das praças da Sé em Lisboa e em São Paulo. En C. Fortuna y R. Proença Leite, (orgs.), Diálogos urbanos: terrotórios, cultura, patrimonios (pp. 127-174). Coimbra, Portugal: Almedina.

Fu-Tuan, Y. (1977). Space and place: The perspective of experience. Minneapolis, MN: University of Minnesota.

García del Villar, R. (2018). Identidades de los paisajes urbanos. Usos y puestas en valor. En B. Calderón Roca (coord.), Valores e identidad de los paisajes culturales. Instrumentos para el conocimiento y difusión de una nueva categoría patrimonial (pp. 177-200). Granada, España: Universidad de Granada.

Gehl, J. (2006). La humanización del espacio urbano. La vida social entre los edificios. España: Reverte.

Giglia, A. (2001). Sociabilidad y megaciudades. Estudios Sociológicos, 19(3), 799-821. Recuperado de https://estudiossociologicos.colmex. $\mathrm{mx} /$ index.php/es/article/view/497/0 
Gomes, M. (2007) De largo a jardim: praças públicas no Brasil, algumas aproximações. Estudos Geográficos, 5(1), 101-120. Recuperado de https://www.periodicos.rc.biblioteca.unesp.br/index.php/estgeo/ article/view/967

Gomes, P. (2012). Espaços públicos: um modo de ser do espaço, um modo de ser no espaço. En I. Castro, P. C. Costa Gomes y R. Lobato Correa (coords.), Olhares geográficos: modos de ver e viver o espaço (pp.1941). Brasil: Bertrand.

Gomes, P. y Parente, L. (2018). Sociabilidad pública en los parques urbanos de Río de Janeiro. En C. Egea y S. Coupleux (coords.), Ciudad, vivir, habitar (pp. 169-182). Granada, España: Universidad de Granada.

Habermas, J. (1981). Historia y crítica de la opinión pública. La transformación estructural de la vida pública. Barcelona, España: Gustavo Gilli.

Hernández, E. y Guérin, F. (2016). La experiencia de la caminata urbana durante la noche. Alteridades, 26(52), 35-50. Recuperado de http://www.scielo.org.mx/scielo.php?script=sci_arttext\&pid=S018870172016000200035

Herzer, H. y Gil, L. (2012). Barrios al sur. Renovación y pobreza en la ciudad de Buenos Aires. Argentina: Café de las Ciudades.

Lamas, J. (1993). Morfologia urbana e desenho da cidade. Brasil: Fundação Calouste Gulbenkiana.

Lamborghini, E. (2015). Candombe afro-uruguayo en Buenos Aires: nuevas formas de sociabilidad, política y apropiación del espacio público. (Tesis doctoral, Universidad de Buenos Aires, Facultad de Filosofía y Letras). Recuperado de http://repositorio.filo.uba.ar/handle/ filodigital/6024

Lan, D. y Migueltorena, A. (2011). Formas de apropiación y espacios públicos en Tandil, a inicios del siglo XXI. Cuaderno Urbano. Espacio, Cultura, Sociedad, 10(10), 107-126. Recuperado de http://revistas.unne. edu.ar/index.php/crn/article/view/581

Lépore, S. (2012). Sociabilidad e integración social en las villas de Bajo Flores y de Barracas. En E. Lépore, A. Mitchell, D. Leis, E. Rivero, J. Macció y S. Lépore (coords.), Capacidades de desarrollo y sociedad civil en las villas de la ciudad (pp. 205-265). Argentina: Educa.

Licona, E. (coord.). (2007). El zócalo de la ciudad de Puebla. Actores y apropiación social del espacio. México: Benemérita Universidad Autónoma de Puebla

Lindón, A., Hiernaux-Nicolas, D. y Aguilar, M. A. (2006). De la espacialidad, el lugar y los imaginarios urbanos: a modo de introducción. En A. 
Lindón, D. Hiernaux y M. Aguilar (coords.), Lugares e imaginarios en la metrópolis (pp. 9-25). Ciudad de México: Anthropos.

Low, S. (1997). Urban public spaces as representations of culture: The plaza in Costa Rica. Environment and Behavior, 29(1), 3-33. Recuperado de https://journals.sagepub.com/doi/10.1177/001391659702900101

Marcús, J. (2012). Procesos de renovación urbana: hacia la "marca Buenos Aires" desde el "modelo Barcelona". Ponencia presentada en VII Jornadas de Sociología de la Universidad Nacional de La Plata, La Plata, Argentina.

Medeiros, I. (2016). Población sin hogar y la espacialidad de la vida cotidiana: entre la supervivencia y la sociabilidad en la (im)posible ciudad de Río de Janeiro. En C. Egea y D. Sánchez (eds.), Ciudades amigables. Perspectivas, políticas, practicas (pp. 211-231). España: Comares.

Monteys, X. (2017). La calle y la casa. Urbanismo de interiores. Barcelona, España: Gustavo Gili.

Motta, J., Rosa, P. y García, A. (2013). Perspectivas y tensiones del espacio público: los habitantes de la calle en la Ciudad Autónoma de Buenos Aires. Cuaderno Urbano. Espacio, Cultura, Sociedad, 15(15), 49-70. Recuperado de http://www.redalyc.org/articulo.oa?id=369233935003

Núñez, A. e Higueras, E. (2018). Altitud, variables climáticas y tiempo de permanencia de las personas en plazas de Ecuador. Urbe. Revista Brasileira de Gestao Urbana, 10(2), 414-425. Recuperado de http://www. scielo.br/pdf/urbe/v10n2/2175-3369-urbe-2175-3369010002AO11. pdf

Ortiz, A. (2006). Uso de los espacios públicos y construcción del sentido de pertenencia de sus habitantes en Barcelona. En A. Lindón, D. Hiernaux-Nicolas, M. A. Aguilar (coords.), Lugares e imaginarios en la metrópolis (pp. 67-83). Ciudad de México: Anthropos.

Páramo, P. (2010). El espacio público y la calidad de vida urbana. En P. Páramo y M. García (eds.), La dimensión social del espacio público. Aportes para la calidad de vida urbana. Bogotá, Colombia: Universidad Santo Tomás / Universidad Pedagógica Nacional.

Páramo, P. (2011). Sociolugares. Bogotá, Colombia: Universidad Piloto de Colombia.

Perelman, M. (2018). Disputas en torno al uso del espacio público en Buenos Aires. Caderno CRH, 31(82), 87-98. Recuperado de https://dx.doi. org/10.1590/s0103-49792018000100006

Pérez, E. (2004). La percepción del espacio público. Revista Bitácora Urbano Territorial, 1(8), 27-31. Recuperado de https://revistas.unal.edu. co/index.php/bitacora/article/view/18753 
Petzold, A. (2017). ¿Público para quién? La performatividad de los límites del espacio público. Puebla, México: Fundación Universidad de las Américas.

Rabotnikof, N. (2008). Discutiendo lo público en México. En M. Merino (coord.), ¿Qué tan público es el espacio público en México? (pp. 2556). México: Fondo de Cultura Económica / Universidad Veracruzana. Ramírez, P. (2007). La ciudad, espacio de construcción de ciudadanía. Revista Enfoques: Ciencia Política y Administración Pública, 7, 85-107. Recuperado de https://dialnet.unirioja.es/servlet/articulo?codigo $=2509016$

Ramírez, P. (2016). La reinvención del espacio público en el lugar central. Desigualdades urbanas en el barrio de La Merced, Centro Histórico de la Ciudad de México. En P. Ramírez Kuri (coord.), La reinvención del espacio público en la ciudad fragmentada (pp. 99-134). Ciudad de México: Universidad Nacional Autónoma de México.

Rizzo, P. (2010). El rol de los espacios públicos en los barrios suburbanos de la ciudad de Mendoza. Ponencia presentada en el XI Coloquio Internacional de Geocrítica, Barcelona.

Rodríguez, M. (2014). Los perros como catalizadores de socialización y de cambio en espacios públicos. Reflexiones, 93(1), 113-120. Recuperado de http://www.redalyc.org/articulo.oa?id=72930086008

Rodríguez, M.C., Arqueros, S., Rodríguez, M.F., Gómez, M. y Zapata, M. (2011). La política urbana "PRO": continuidades y cambios en contextos de renovación en la Ciudad de Buenos Aires. Cuaderno Urbano. Espacio, cultural, sociedad, 11(11), 101-121. Recuperado de http:// www.redalyc.org/articulo.oa? id $=369236772005$

Rojas, E. (2004) Volver al centro. La recuperación de las áreas urbanas centrales. Nueva York: Banco Iberoamericano de Desarrollo.

Romagnoli, V. (2006). Espacios verdes públicos: entre el paradigma del Estado y su resignificación a través del uso. Estudio de casos: plaza de 25 de mayo de 1810 y Plaza Hussay (Buenos Aires). Argentina: Universidad Nacional del Nordeste (Jornadas de Investigación, 4).

Romero, L. (1999). Latinoamérica: las ciudades y las ideas. Medellín, Colombia: Universidad de Antioquia.

Rubio, A. (2016). La calle, el café y el prostíbulo. Espacios de sociabilidad en la obra de Pedro Herreros (1890-1937), un poeta español emigrante en Buenos Aires. Historia Caribe, 11(28), 77-108. Recuperado de http://www.scielo.org.co/pdf/hisca/v11n28/v11n28a05.pdf

Salazar, O. (2007). Tiempo libre al aire libre. Prácticas sociales, espacio público y naturaleza en el Parque Nacional Enrique Olaya Herrera (1938- 
1948). Historia Crítica, 33, 186-208. Recuperado de http://www. scielo.org.co/pdf/rhc/n33/n33a08.pdf

Salazar, C. (2017). Plaza fundacional en el siglo XX: la transformación en Lima, Bogotá y Santiago a través de los concursos arquitectónicos. Bogotá, Colombia: Universidad Nacional de Colombia.

Salinas, L. (2013). Gentrificación en la ciudad latinoamericana. El caso de Buenos Aires y Ciudad de México. Revista Digital para Estudiantes de Geografia y Ciencias Sociales. GeoGraphos, 4(44), 283-307. Recuperado de https://web.ua.es/es/revista-geographos-giecryal/documentos/ luis-salinas.pdf

Salmenkari, T. (2009). Geography of protest: Places of demonstration in Buenos Aires and Seoul. Journal Urban Geography, 30(3), 239-260. Recuperado de https://www.tandfonline.com/doi/abs/10.2747/02723638.30.3.239

Scarpaci, J. (2005). Plazas and barrios: Heritage tourism and globalization in the Latin American, centro histórico. Tucson, AZ: University of Arizona.

Scobie, J. (1982). Consideraciones acerca de la atracción de la plaza en las ciudades provinciales argentinas, 1850-1900. En AAVV, De historia e historiadores. Homenaje a José Luis Romero. Ciudad de México: Siglo XXI.

Segarra, S. (2016). Mobiliario urbano, imagen y ciudad. En S. Segarra, L. M. Valenzuela y J. L. Rosúa (coords.), Paisaje contexto. Naturaleza, jardin, espacio público. Granada, España: Universidad de Granada.

Segovia, O. y Neira, H. (2005). Espacios públicos urbanos: una contribución a la identidad y confianza social y privada. Revista INVI, 20(55), 166-182. Recuperado de http://www.revistainvi.uchile.cl/index.php/ INVI/article/view/324/888

Sennett, R. (2002). El declive del hombre público. Barcelona, España: Península.

Serpa, P. (2003). Apropriação social versus requalificação dos parques e praças na capital baiana. En J. Esteve y U. Uriarte (orgs.), Panoramas urbanos: reflexões sobre a cidade (pp. 121-139). Salvador, Brasil: EDUFBA.

Síbori, H. (2005). Locas, chongos y gays: sociabilidad homosexual masculina durante la década de 1990. Buenos Aires, Argentina: Antropofagia.

Simonetto, P. (2017). Fronteras del deseo. Homosexualidad, sociabilidad y afecto en la Ciudad de Buenos Aires (1950-1983). Cadernos Pagu, 49. Recuperado de http://www.scielo.br/scielo.php?pid $=$ S0104-83332017000100502\&script $=$ sci_abstract\&tlng $=$ es 
Sousa, E. (2013). El espacio público. Una visión interpretativa desde la posición de Jürgen Habermas y Hannah Arendt. En D. Sánchez González, y C. Egea Jiménez (coords.), La ciudad un espacio para la vida. Miradas y enfoques desde la experiencia espacial (pp. 43-58). Granada, España: Universidad de Granada.

Spirn, A. (1995). O jardim de granito: a natureza no desenho da cidade. São Paulo, Brasil: Edusp.

Thomasz, A. G. (2010). Debajo de la alfombra de los barrios del sur. Derecho a la ciudad o nuevas formas de higienismo. Intersecciones en Antropologia, 11(1), 15-27. Recuperado de http://www.ridaa.unicen.edu. ar/xmlui/handle/123456789/1173

Thuillier, G. (2005). El impacto socio-espacial de las urbanizaciones cerradas: el caso de la Región Metropolitana de Buenos Aires. Revista Eure, 31(93), 5-20. Recuperado de https://scielo.conicyt.cl/pdf/eure/v31n93/ art01.pdf

Torres, F. (2008). Los nuevos vecinos en la plaza. Inmigrantes, espacios y sociabilidad pública. Revista de Antropología Iberoaméricana, 3(3), 336-397. Recuperado de https://dialnet.unirioja.es/servlet/articulo? codigo $=2728463$

Treviño, J. (2013). La dimensión pública del espacio urbano. Relevancia de plazas, paseos y parques vecinales para la generación, mantenimiento y reproducción de la sociedad civil. En D. Sánchez González y C. Egea Jiménez (coords.), La ciudad, un espacio para la vida. Miradas y enfoques desde la experiencia espacial (pp. 37-42). Granada, España: Universidad de Granada.

Vega, D. (2015). Análisis del concepto de sociabilidad en las ciencias sociales. Revista ABRA. Revista de la Facultad de Ciencias Sociales, 35(51), 1-13. Recuperado de https://www.revistas.una.ac.cr/index.php/ abra/article/view/7538/7917

Webb, M. (1990). The city square. Londres, Inglaterra: Thames and Hudson.

\section{Acerca de los autores}

Carmen Egea Jiménez es doctora en Geografía por la Universidad de Granada. Es docente del Departamento de Geografía Humana e investigadora del Instituto de la Paz y los Conflictos de la Universidad de Granada. Actualmente es directora de la Colección Eirene-Editorial UGR. Sus principales líneas de investigación son: vulnerabilidad social, derecho a la ciudad y espacios públicos. ORCID: http://orcid.org/0000-0002-6629-6890 
Entre sus publicaciones recientes se encuentran:

Egea Jiménez, C. y Checa Olmos, F. (2019). Marxismo y paz. Reflexiones desde las ciencias sociales. En S. Cayuela, K. Schriewer y D. Martínez (coords.), Dialécticas de la alteridad. Antropología y marxismo a comienzos del siglo XXI (159-170). Barcelona, España: Bellaterra.

Egea Jiménez, C. y Coupleux, S. (coords.). (2018). Ciudad, vivir, habitar. Granada, España: Universidad de Granada.

Edwar Leonardo Salamanca Ospina es doctor en Ciencias Sociales, por la Universidad de Granada; maestro en Cultura de Paz, Conflicto, Educación y Derechos Humanos, por la Universidad de Cádiz; y licenciado en Ciencias Sociales, por la Universidad Pedagógica Nacional de Colombia. Actualmente es docente de planta en la Secretaría de Educación de Distrito (SED) de Bogotá. Sus principales líneas de investigación son: conflicto y paz en Colombia, y restitución de tierras y espacios públicos. ORCID: https://orcid. org/0000-0001-6930-8423

Entre sus publicaciones recientes se encuentran:

Salamanca Ospina, L. y Egea Jiménez, C. (2019). Conflicto por la tierra: retorno y restitución de tierras en la finca El Carpintero (Colombia). Documents d'Anàlisi Geogràfica, 65(1), 115-138. DOI: https://doi. org $/ 10.5565 / \mathrm{rev} / \mathrm{dag} .455$

Salamanca Ospina, E. L. y Egea Jiménez, C. (2018). Vulnerabilidad social de la población desterrada. Más allá del goce efectivo de derechos (2018). Revista de Ciencias Sociales, 24(4), 38-56. Disponible en https://www. redalyc.org/jatsRepo/280/28059581004/28059581004.pdf

Salamanca Ospina, E. L. (2017). Colombianos en las fronteras: perspectivas sobre el refugio. En F. Soulages y P. San Ginés Aguilar (coords.), Fronteras, memoria y exilio (pp. 107-126). Granada, España: Eirene- L Harmattan.

Recepción: 26 de julio de 2018.

Aceptación: 14 de mayo de 2019. 